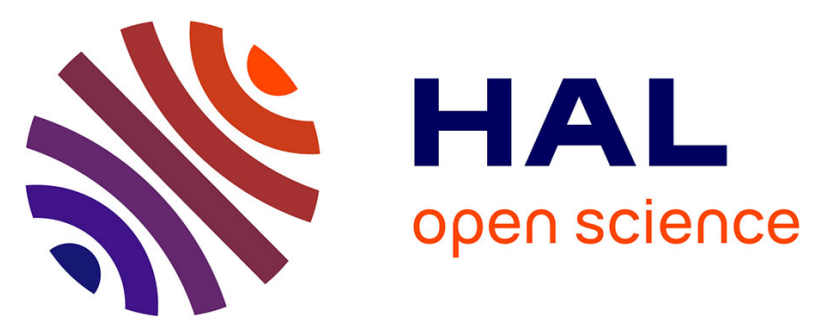

\title{
Experimental and Model-Based Investigation of the Effect of the Free-Surface Flow Regime on the Detection Threshold of Warm Water Inflows
}

Hugo Le Lay, Zahra Thomas, Olivier Bour, Francois Rouault, Pascal Pichelin, Florentina Moatar

\section{To cite this version:}

Hugo Le Lay, Zahra Thomas, Olivier Bour, Francois Rouault, Pascal Pichelin, et al.. Experimental and Model-Based Investigation of the Effect of the Free-Surface Flow Regime on the Detection Threshold of Warm Water Inflows. Water Resources Research, 2020, 56 (2), pp.e2018WR023722. 10.1029/2018WR023722 . insu-02533350

\section{HAL Id: insu-02533350 \\ https://hal-insu.archives-ouvertes.fr/insu-02533350}

Submitted on 6 Apr 2020

HAL is a multi-disciplinary open access archive for the deposit and dissemination of scientific research documents, whether they are published or not. The documents may come from teaching and research institutions in France or abroad, or from public or private research centers.
L'archive ouverte pluridisciplinaire HAL, est destinée au dépôt et à la diffusion de documents scientifiques de niveau recherche, publiés ou non, émanant des établissements d'enseignement et de recherche français ou étrangers, des laboratoires publics ou privés. 


\section{Water Resources Research}

\author{
RESEARCH ARTICLE \\ 10.1029/2018WR023722 \\ Key Points: \\ - Thermal anomalies induced by \\ warm inflows have lower \\ amplitudes under laminar flow \\ conditions \\ - The inflow signal can be diluted in a \\ volume created by an imposed water \\ stage (weir) and be dispersed \\ upstream under subcritical flow \\ - Atmospheric exchanges cannot be \\ overlooked at low velocities \\ combined with low thermal contrast \\ between flume water and injected \\ water
}

Supporting Information:

- Supporting Information S1

Correspondence to:

Z. Thomas,

zahra.thomas@agrocampus-ouest.fr

Citation:

Le Lay, H., Thomas, Z., Bour, O., Rouault, F., Pichelin, P., \& Moatar, F. (2020). Experimental and model-based investigation of the effect of the free-surface flow regime on the detection threshold of warm water inflows. Water Resources Research, 56, e2018WR023722. https://doi.org/ 10.1029/2018WR023722.

Received 30 JUL 2018 Accepted 26 DEC 2019 Accepted article online 25 JAN 2020

(C)2020. American Geophysical Union. All Rights Reserved.

\section{Experimental and Model-Based Investigation of the Effect of the Free-Surface Flow Regime on the Detection Threshold of Warm Water Inflows}

\author{
Hugo Le Lay ${ }^{1,2}$ (D) Zahra Thomas ${ }^{1}$ (D) Olivier Bour ${ }^{3}$, François Rouault ${ }^{1}$, Pascal Pichelin ${ }^{1}$, \\ and Florentina Moatar ${ }^{2,4}$ iD \\ ${ }^{1}$ UMRSAS, INRAE, AGROCAMPUS OUEST, Rennes, France, ${ }^{2}$ Université de Tours EA 6293 GeoHydrosystemes \\ continentaux, Parc de Grandmont, Tours, France, ${ }^{3}$ Université Rennes, CNRS, Geosciences Rennes UMR 6118, Rennes, \\ France, ${ }^{4}$ INRAE, RiverLy, Ctr Lyon Villeurbanne, Villeurbanne, France
}

\begin{abstract}
Heat has been used as a tracer to identify and quantify groundwater inflows into streams. Over the last decade, a few methods have used fiber-optic distributed temperature sensing to facilitate assessment of such inflows into small streams. However, these methods focused mainly on the groundwater percentage and the thermal contrast between groundwater and surface water without considering the flow regime of the surface water. In this study, artificial water inflows into a controlled flume were examined using fiber-optic distributed temperature sensing to quantify the thermal anomalies induced as a function of the flow regime (turbulent or laminar). Computer simulations were then performed to widen the range of the parameters tested and provide insight into the physical processes involved. Experiments conducted under the turbulent regime were in accordance with results and uncertainties of previous studies. Under the laminar regime, however, the inflow-induced thermal anomalies were always smaller than those under the turbulent regime for a given inflow percentage. Therefore, the actual inflow percentage may be underestimated when using a classic method under a laminar regime.
\end{abstract}

\section{Introduction}

Over the past few years, greater importance has been placed on quantifying groundwater inflows into streams due to their effects on stream flow and quality. Hyporheic exchanges between streams and groundwater are typically considered to be key controls on the biogeochemical processes within stream networks (Fox et al., 2016; Zarnetske et al., 2011). Concentrated point-source groundwater discharges, however, are easier to assess and are essential for the water balance and ecological functions of small streams (Lowry et al., 2007; Selker, van de Giesen, et al., 2006; M. C. Westhoff et al., 2011). Locations of concentrated groundwater inflows, which are generally related to subsurface heterogeneities as well as open faults and artificial agricultural drains, are fundamental for fish reproduction (Dugdale et al., 2013; Ebersole et al., 2003; Geist et al., 2002), denitrification processes (Krause et al., 2013), and biogeochemical hot spots in riparian zones (Conant, 2004; Vidon et al., 2010). Hence, locating and quantifying groundwater inflows into streams is of great importance for optimal management of stream water and groundwater (Smith et al., 2008).

Temperature has been used for many years as an effective proxy for hydrological processes (Anderson, 2005; Conant, 2004; Constantz, 1998). Fiber-optic distributed temperature sensing (FO-DTS) has been used successfully over the last decade to locate and quantify localized groundwater inflows (Briggs et al., 2012; Selker, Thevenaz, et al., 2006; Tyler et al., 2009) or for different runoff processes identification (M. C. Westhoff, 2011). FO-DTS allows for continuous acquisition of measurements over both time and space along a cable embedded within a streambed or within the water column. Depending on the integration time and cable deployment of the system configuration, FO-DTS can estimate temperature with high accuracy in temperature (down to $0.01{ }^{\circ} \mathrm{C}$ ) and has impressive spatial resolution (down to $0.25 \mathrm{~m}$ using the most recent monitoring systems). Since groundwater temperature is much more stable over time than that of surface water (Constantz, 2008), spots of groundwater upwelling can be detected by studying the spatiotemporal temperature variability along a fiber-optic cable during an entire diurnal or annual cycle (Henderson et al., 2009; 
Matheswaran et al., 2015; Mwakanyamale et al., 2012). Thus, groundwater inflows can be distinguished from other potential causes for thermal heterogeneities within a stream such as hydromorphology (Dugdale et al., 2015) or vegetation shading. Excellent results have been obtained when punctual measurements were acquired during the peak contrast between surface water and groundwater temperatures (i.e., in the dawn or afternoon during the winter or summer) (Hare et al., 2015; Selker, van de Giesen, et al., 2006).

Certain metrics take advantage of FO-DTS characteristics to quantify localized groundwater inflows. The temporal lag between two cables embedded at different depths within an artificial flume streambed has been used in conjunction with heat transport equations to calculate vertical flow velocity and discharge through sediments (Mamer \& Lowry, 2013). The same approach can be used with thermal lances, which measure water temperature in a streambed at different depths (Briggs et al., 2012; Gonzalez-Pinzon et al., 2015), although this approach requires prior knowledge of groundwater inflow locations. The amplitude of the temperature difference between a groundwater-influenced section and an upstream section obtained by embedding a fiber-optic cable at a single, unique shallow depth or by simply placing the cable atop a streambed can also be used to estimate groundwater inflow [F Selker \& Selker, 2014]. This particular method requires coupling an FO-DTS system with stream discharge measurements and independent temperature measurements of the groundwater itself (Selker, Thevenaz, et al., 2006; M. C. Westhoff et al., 2011; M. C. Westhoff et al., 2007). Moreover, it assumes complete mixing of the two types of water without any heat loss. Despite this simplification, the results acquired using this approach are compatible with methods that use chemical tracers such as radon (Briggs et al., 2012). Lauer et al. (2013) showed that an artificial inflow percentage as low as $2 \%$ of the upstream discharge remains detectable via FO-DTS using this method; the corresponding uncertainties ranged from $9-22 \%$ when the thermal anomalies were well above the accuracy of the FO-DTS system $\left(0.04{ }^{\circ} \mathrm{C}\right.$ according to the manufacturer and $0.24{ }^{\circ} \mathrm{C}$ after manual verification $)$. This inflow percentage is of great importance for the detectability of thermal anomalies. Additionally, the thermal contrast $\Delta T$ between the injected water and stream water was found to be the main contributor to the amplitude of these thermal anomalies. However, the experiments of Lauer et al. (2013) were conducted in a small natural stream with only two or three stream discharge measurements (primarily 1.3 $\mathrm{L} / \mathrm{s}$, with an additional 6.5 or $7.1 \mathrm{~L} / \mathrm{s}$ ) to obtain the range of inflow percentages. Their study revealed substantial temperature differences between anomalies that depended upon stream discharge, and these differences were assigned to uncertainties produced by a low signal-to-noise ratio; however, other parameters such as the flow regime could explain some of the differences in these anomalies.

Our research aimed to determine whether methods that assume perfect mixing of water with no heat loss are always suitable for quantifying focused groundwater inflows under different flow regimes. To do so, we quantified a thermal anomaly along a flume caused by a warm inflow. Three variables were tested:

i flow regime as a function of stream discharge $Q$ and the relevant Reynolds number;

ii $P$ defined as the percentage of inflow $\mathrm{q}$ in total stream discharge $\left[P=\frac{q}{Q_{T}} \times 100\right],\left[Q_{T}=\mathrm{q}+\mathrm{Q}\right]$;

iii thermal contrast $\Delta T$ between flume water and the injected inflow.

To assess and distinguish the influence of each variable on quantification of the thermal anomaly, we first performed point injection experiments within a hydraulic flume monitored with FO-DTS. The results of these experiments were then used to calibrate a 1-D heat-transport model. This model allowed wider ranges of variables to be explored under steady-state conditions to understand the key processes involved.

\section{Materials and Methods}

\subsection{Flume Experiments and Data Collection}

Flume experiments consisted of artificial injections of warm water into a $22 \mathrm{~m}$ long flume with controlled free-surface flow. The flume is made of concrete and embedded into the ground. Located outdoors, the flume has a trapezoidal cross section with a basal width of $0.45 \mathrm{~m}$, an upper width of $0.85 \mathrm{~m}$ and a depth of $0.40 \mathrm{~m}$ (Figure 1). The longitudinal slope of the flume is $0.01 \%$. The upstream flume discharge $Q$ was regulated using a gate valve. Discharge was measured manually using a built-in Parshall system and a ruler before and after each injection test. The water stage was set to a minimum of $0.20 \mathrm{~m}$ using a weir located downstream, and it was occasionally measured with a ruler both 1 and $12 \mathrm{~m}$ away from the injection point. These experiments were performed on 6-7 June 2016 under sunny conditions; thus, the temperature difference between flume 


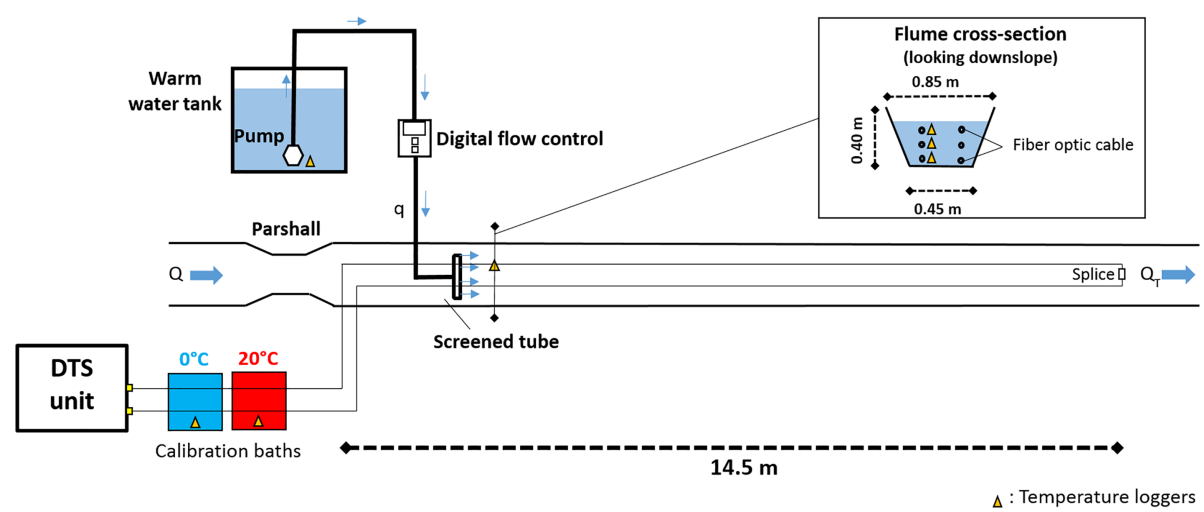

Figure 1. Experimental design used for the injection of warm water along a concrete flume. Injections were performed through a tube connected to the warm water tank using a pump. The fiber-optic distributed temperature sensing (FO-DTS) system was deployed at three depths and two lines with a double-ended setup, resulting in six measuring sections of cable. Two calibration baths were used to adjust the FO-DTS data, and highly accurate RBRsolo temperature loggers were used to monitor the bath temperatures and validate FO-DTS measurements in the flume.

water and the air was $\sim 9-10{ }^{\circ} \mathrm{C}$. We considered the concrete flume's temperature to be constant during experiments due to its embedded nature and the relatively deep depth of the flowing water. Other meteorological conditions such as wind velocity, cloudiness, relative humidity, and shortwave radiation were obtained from the nearest Meteo France weather station ( $6 \mathrm{~km}$ away), recording on an hourly basis. Unfortunately, measuring longwave radiation from the surrounding environment was not possible at the time.

Warm water was injected at a specific location to imitate a hypothetical focused groundwater inflow. To do so, we used an MP1 pump (Grundfos Ltd., Denmark) connected to a tank of $1 \mathrm{~m}^{3}$ filled with warm water $(\Delta T$ between tank and flume waters was $2.8-3.3^{\circ} \mathrm{C}$ ). The warm water was injected through a screened hose loop placed at the bottom of the flume $3 \mathrm{~m}$ downstream from the Parshall system, where the flow was considered undisturbed by the slope break. The thermal contrast $\Delta T$ between flume and tank waters was maintained by manually adding hot water into the tank. Tank water was injected only after thoroughly mixing it with a stick. Handheld temperature measurements inside the tank using a PT100 sensor (accuracy of $0.15{ }^{\circ} \mathrm{C}$ ) allowed us to ensure that the injected water temperature remained constant. An independent RBRsolo temperature logger (RBR Ltd., Kanata, Ontario, Canada; accuracy of $0.002{ }^{\circ} \mathrm{C}$ ) was placed at the bottom of the tank to monitor the injected water over time. The $\Delta T$ of each experiment was obtained by comparing the temperature from this RBRsolo logger to the temperature upstream of the injection point provided by the FO-DTS system. Note that no cold water injections were performed because of the difficulty in maintaining the temperature of a cold bath of such volume constant for such a duration.

Because the injection pump allowed only a small range of inflow discharges $q$, flume discharges $Q$ were chosen to ensure that the inflow percentage $P$ ranged from a few percent to 50\%. Of the 12 experiments performed, 10 were successful, with values of $P$ ranging from $4-41 \%$ at two discharge rates $(Q=3.6$ and $0.8 \mathrm{~L} / \mathrm{s})$ and six values of $q$ ranging from $0.16-0.57 \mathrm{~L} / \mathrm{s}$. Two of the 12 experiments $(Q=0.8 \mathrm{~L} / \mathrm{s})$ failed due to nonconstant flume discharges. Experiments with $Q=3.6 \mathrm{~L} / \mathrm{s}$ lasted 12-18 min, while those with $0.8 \mathrm{~L} / \mathrm{s}$ lasted 18-22 min. This duration was chosen to ensure that injection reached a steady state, or at least a quasi-steady state. Indeed, since the tank had a relatively small volume $\left(1 \mathrm{~m}^{3}\right)$, the duration of injection had to remain relatively short.

For all experiments, flume water temperature was monitored over $14.75 \mathrm{~m}$ by FO-DTS, using a $10 \mathrm{~mm}$ wide fiber-optic cable with Kevlar protection and black polyamide jacket (Silixa Ltd.) deployed along the flume. Due to its thickness and construction, the cable was suspected to have thermal inertia too high to be able to monitor high frequency variations. Preliminary comparisons of FO-DTS and the RBRsolo loggers, however, showed that the cable was able to monitor relatively high frequency variations $(<30 \mathrm{~s})$ such as our punctual warm injections. To prevent detection problems, injection experiments were designed to last as long as possible. The initial length of the cable was $470 \mathrm{~m}$, but only the last $250 \mathrm{~m}$ were 
deployed in the flume. To explore the spatial variability of temperature along the water stage and flume length, the cable was intertwined at three different stages (heights of 0,8 , and $19 \mathrm{~cm}$ from the bottom) and placed at two width positions along the flume (Figure 1). Stainless-steel frames anchored to the banks every $2 \mathrm{~m}$ allowed the cables to be straightened along the flume. The FO-DTS unit (Ultima-XT, Silixa Ltd.) was used in a double-ended duplexed configuration (van de Giesen et al., 2012), with a 20 s initial integration time and spatial sampling of $25 \mathrm{~cm}$, for a final spatial resolution of 50-75 cm. The integration time was a trade-off between injection timing, the thermal inertia of the cable and the accuracy of the measurements achieved.

Cold and warm calibration baths were placed before the flume (Figure 1), approximately in the middle of the total length of cable. The cold bath was a mixture of ice and water, while two aquarium heaters maintained the warm bath. Two bubblers in each bath mixed them. These baths were monitored simultaneously by PT100 probes integrated into the FO-DTS unit (Silixa Ltd., Elstree, UK; accuracy of $0.1{ }^{\circ} \mathrm{C}$ ) and by independent RBRsolo temperature loggers. Because of their difference in accuracy, two calibrations were attempted. One was performed directly by the FO-DTS unit using its PT100 probes, while the other was based on van de Giesen et al. (2012) and Hausner et al. (2011) using the RBRsolo loggers. No validation bath was used, but three additional RBRsolo loggers were installed in the flume for validation purposes, $0.5 \mathrm{~m}$ downstream of the injection point and at each stage $(0,8$, and $19 \mathrm{~cm}$ ) (Figure 1). These three RBRsolo loggers were attached to the left portion of the fiber-optic cable. The quality of the calibration of FO-DTS measurements was assessed using mean bias and root-mean-square error (RMSE) (Table 1). Since this quality depends on external conditions (e.g., air temperature and bends in the cable), these metrics were calculated for each experiment. Overall, manual calibration gave better results than the manufacturer's calibration ( $R M S E=0.113-0.197^{\circ} \mathrm{C}$ and $0.175-0.389^{\circ} \mathrm{C}$, respectively). The uncertainty in each experiment's measurements was based on the manual RMSE calculated for it.

\subsection{Computer Simulations Based on Experiments}

Computer simulations were performed to efficiently compare the influence of different flow regimes on thermal anomaly amplitudes, due to simulation's ability to finely control variables. If the flow regime caused differences in thermal anomalies, computer simulations would help understand the fine-scale physics governing the processes. These simulations allowed clear steady-state conditions to be assessed. Simulations were performed using the 1-D version of HEC-RAS 5.0 (U.S. Army Corps of Engineers, Davis, California, USA). To use a 1-D model based on 3-D experiments, we assumed that mixing in the flume was very good, and thus, that flume temperature was not stratified. We first calibrated Manning and dispersion the model using results of four (out of 10$)$ experiments $(P=8 \%, 10 \%, 38 \%$, and $41 \%$ ), using their measurements as boundary conditions. Concerning the heat transport module (aka "water quality"), no thermal boundary condition was set downstream since previous tests showed no real effect on the results. Nonetheless, to our knowledge, the HEC-RAS water quality module does not allow the heat budget at the air-water interface to be turned off, adding unwanted input and outputs to the model.

These simulation results were then compared to the corresponding experiments. Once the model was calibrated, we constructed new simulations with constant thermal parameters and longer injections.

HEC-RAS was initially developed as a hydraulic modeling system based on Saint-Venant dynamic flow equations to which was added a water quality modeling extension (Drake et al., 2010). The latter allowed us to resolve the advection-dispersion equation under 1-D free flow coupled to an energy budget, the whole of which was applied to each cell (i.e., cross section) of the modeled flume at multiple time steps. The energy budget determines whether a given cell is losing (sink) or gaining heat (source) depending on the weather conditions and water temperature and volume. It can be written using equations of Drake et al. (2010):

$$
H=\frac{q_{\text {net }}}{\rho_{w} C_{p w}} \frac{S_{\text {surf }}}{V}
$$

where $H$ is the heat source (or sink) term $\left({ }^{\circ} \mathrm{C} / \mathrm{s}\right), q_{\text {net }}$ is net heat flux at the air-water interface $(\mathrm{W} / \mathrm{m}), \rho_{w}$ is the water's density $\left(\mathrm{kg} / \mathrm{m}^{3}\right), C_{p w}$ is the water's specific heat $\left(\mathrm{J} \cdot \mathrm{kg}^{-1} \cdot{ }^{\circ} \mathrm{C}^{-1}\right), S_{\text {surf }}$ is the air-water surface area $\left(\mathrm{m}^{2}\right)$, and $V$ is the volume of the cross section $\left(\mathrm{m}^{3}\right)$. 
Table 1

Calibration and Validation Metrics Using Manufacturer (Mf.) and Manual Calibration (Ml.) for the 10 Experiments Performed, With Integration Time of $20 \mathrm{~s}$ and Spatial Resolution of $75 \mathrm{~cm}$

\begin{tabular}{lcccccccccc}
\hline \multicolumn{4}{c}{} & \multicolumn{3}{c}{ Calibration metrics: baths } & \multicolumn{3}{c}{ Calibration metrics: flume } \\
\hline \multicolumn{3}{c}{ EXPERIMENT } & \multicolumn{3}{c}{ MB $\left({ }^{\circ} \mathrm{C}\right)$} & \multicolumn{2}{c}{ RMSE $\left({ }^{\circ} \mathrm{C}\right)$} & MB $\left({ }^{\circ} \mathrm{C}\right)$ & \multicolumn{2}{c}{ RMSE $\left({ }^{\circ} \mathrm{C}\right)$} \\
\hline$P$ & $Q(\mathrm{~L} / \mathrm{s})$ & $q(\mathrm{~L} / \mathrm{s})$ & Mf. & Ml. & Mf. & Ml. & Mf. & Ml. & Mf. & Ml. \\
$4 \%$ & 3.6 & 0.16 & 0.152 & $3.6 \mathrm{E}-05$ & 0.211 & 0.059 & 0.190 & 0.150 & 0.190 & 0.150 \\
$6 \%$ & 3.6 & 0.24 & 0.209 & $3.4 \mathrm{E}-05$ & 0.234 & 0.057 & 0.284 & 0.112 & 0.284 & 0.113 \\
$8 \%$ & 3.6 & 0.32 & 0.198 & $3.5 \mathrm{E}-05$ & 0.225 & 0.057 & 0.231 & 0.153 & 0.231 & 0.156 \\
$10 \%$ & 3.6 & 0.41 & 0.143 & $3.4 \mathrm{E}-05$ & 0.215 & 0.058 & 0.215 & 0.120 & 0.215 & 0.123 \\
$12 \%$ & 3.6 & 0.49 & 0.176 & $3.3 \mathrm{E}-05$ & 0.211 & 0.058 & 0.175 & 0.198 & 0.175 & 0.197 \\
$14 \%$ & 3.6 & 0.57 & 0.160 & $3.4 \mathrm{E}-05$ & 0.201 & 0.058 & 0.201 & 0.134 & 0.201 & 0.134 \\
$17 \%$ & 0.8 & 0.16 & 0.160 & $3.3 \mathrm{E}-05$ & 0.198 & 0.059 & 0.269 & 0.064 & 0.269 & 0.143 \\
$29 \%$ & 0.8 & 0.32 & 0.164 & $3.2 \mathrm{E}-05$ & 0.197 & 0.058 & 0.357 & 0.014 & 0.357 & 0.131 \\
$38 \%$ & 0.8 & 0.49 & 0.175 & $3.2 \mathrm{E}-05$ & 0.201 & 0.059 & 0.389 & 0.032 & 0.389 & 0.153 \\
$42 \%$ & 0.8 & 0.57 & 0.159 & $3.2 \mathrm{E}-05$ & 0.186 & 0.059 & 0.347 & 0.029 & 0.347 & 0.147 \\
& & Mean & 0.266 & $3.3 \mathrm{E}-05$ & 0.208 & 0.058 & 0.266 & 0.100 & 0.266 & 0.145 \\
\hline
\end{tabular}

Note. $P=$ percentage of total discharge that is inflow, $Q=$ flume discharge $(\mathrm{L} / \mathrm{s}), q=$ inflow discharge $(\mathrm{L} / \mathrm{s}), \mathrm{MB}=$ mean bias $\left({ }^{\circ} \mathrm{C}\right)$, RMSE $=$ root-mean-square error $\left({ }^{\circ} \mathrm{C}\right)$.

The net heat flux $q_{\text {net }}$ itself is derived from a heat budget:

$$
q_{\text {net }}=q_{s w}+q_{a t m}-q_{b}+q_{h}-q_{l}
$$

where $q_{s w}$ is solar shortwave radiation $\left(\mathrm{W} / \mathrm{m}^{2}\right), q_{a t m}$ is atmospheric incident longwave radiation $\left(\mathrm{W} / \mathrm{m}^{2}\right), q_{b}$ is back longwave radiation $\left(\mathrm{W} / \mathrm{m}^{2}\right), q_{h}$ is sensible heat $\left(\mathrm{W} / \mathrm{m}^{2}\right)$, and $q_{l}$ is latent heat $\left(\mathrm{W} / \mathrm{m}^{2}\right)$. These parameters are calculated from input data provided by the model user such as cloudiness, air temperature, water temperature, atmospheric pressure, and wind speed.

The quantity of energy entering (or exiting) a cross section at each time step is calculated using the explicit numerical method of Leonard (1991) to solve the following equation:

$$
\mathrm{V}^{\mathrm{n}+1} \Phi^{\mathrm{n}+1}=\mathrm{V}^{\mathrm{n}} \Phi^{\mathrm{n}}+\Delta \mathrm{t}\left[\mathrm{Q}_{\mathrm{up}} \Phi_{\mathrm{up}}^{*}-\mathrm{Q}_{\mathrm{dn}} \Phi_{\mathrm{dn}}^{*}+\mathrm{D}_{\mathrm{dn}} \mathrm{S}_{\mathrm{dn}} \frac{\delta \Phi^{*}}{\delta \mathrm{X}_{\mathrm{dn}}}-\mathrm{D}_{\mathrm{up}} \mathrm{S}_{\mathrm{up}} \frac{\delta \Phi^{*}}{\delta \mathrm{X}_{\mathrm{up}}}\right]+\Delta \mathrm{tH}
$$

where, respectively, $V^{n+1}$ and $V^{n}$ are cross-sectional water volumes at the next and current time steps $\left(\mathrm{m}^{3}\right)$ and $\phi^{n+1}$ and $\phi^{n}$ are heat concentrations at the next and current time steps $\left({ }^{\circ} \mathrm{C} / \mathrm{m}^{3}\right)$. Respectively, $\phi_{\text {up }}^{*}$ and $\phi_{d n}^{*}$ are heat concentrations at upstream and downstream cross sections $\left({ }^{\circ} \mathrm{C} / \mathrm{m}^{3}\right)$, and $\frac{\delta \phi^{*}}{\delta X_{u p}}$ and $\frac{\delta \phi^{*}}{\delta X_{d n}}$ are derivatives of upstream and downstream cross sections $\left({ }^{\circ} \mathrm{C} / \mathrm{m}^{4}\right)$. Respectively, $D_{u p}$ and $D_{d n}$ are dispersion coefficients at upstream and downstream cross sections $\left(\mathrm{m}^{2} / \mathrm{s}\right), Q_{u p}$ and $Q_{d n}$ are upstream and downstream flow rates $\left(\mathrm{m}^{3} / \mathrm{s}\right), S_{u p}$ and $S_{d n}$ are upstream and downstream wet areas $\left(\mathrm{m}^{2}\right)$, and $H$ is the cross-sectional energy budget term $\left({ }^{\circ} \mathrm{C} / \mathrm{s}\right)$ calculated from equations (1) and (2).

The geometry of the modeled flume was based on characteristics of the experimental flume: a longitudinal profile of $14.75 \mathrm{~m}$ and a trapezoidal cross section. A broad-crested weir geometrically similar to the one used for experiments was added at the end of the modeled flume. The Manning coefficient was set to $0.012 \mathrm{~s} / \mathrm{m}^{1 / 3}$, close to literature values for concrete. A mesh size of $25 \mathrm{~cm}$ and a $20 \mathrm{~s}$ simulation time step were chosen to match experimental conditions and the FO-DTS configuration. Since no medium (sand or gravel) was used to buffer the warm injection during experiments, we described the modeled injection as lateral inflow rather than groundwater inflow. This simplification of the inflow was possible because of the 1-D approach. The lateral inflow was set $2 \mathrm{~m}$ from the upstream boundary. Meteorological parameters such as cloudiness, atmospheric pressure, and wind speed came from the same Meteo France weather station mentioned for experiments. Air temperature came from on-site measurements. Ultimately, the model was adjusted to match the experimental results (Figure 3) by manually changing the dispersion coefficient: It was finally set to $0.025 \mathrm{~m}^{2} / \mathrm{s}$ and considered constant along the flume. 


\subsection{Computer Simulations Based on the Calibrated Model}

A set of new simulations was created to explore more variables and their effects on downstream temperature. First, three thermal contrasts $\Delta T$ between injected water and flume water $\left(\Delta T=0.5,2\right.$, and $\left.4{ }^{\circ} \mathrm{C}\right)$ were modeled. Then, for each $\Delta T$, the effect of five flow regimes was explored by changing the upstream flume discharge $Q(1,5,10,20$, and $30 \mathrm{~L} / \mathrm{s})$. Finally, for each $Q$, six fixed inflow percentages $P$ were tested: $5 \%, 9 \%$, $17 \%, 23 \%, 29 \%$, and $33 \%$ of the total discharge $Q_{T}$. In the end, 90 simulations were performed $(3 \Delta T \times 5 Q \times 6 P)$.

Simulations were set up as follows: (i) free flow with no injection for $3 \mathrm{~min}$, then (ii) injection of warm water for $90 \mathrm{~min}$ to ensure that a steady state was reached, even at the lowest discharges. Since flow boundary conditions required a downstream water stage that matched the upstream discharge, each applied discharge $Q$ $(1,5,10,20$, and $30 \mathrm{~L} / \mathrm{s})$ was associated with a respective water stage $(2,4,6,10$, and $13 \mathrm{~cm})$, roughly estimated from direct measurements (made with a ruler) in the flume, downstream of the weir. A sensitivity analysis (Figure S2 and Table S1 in the supporting information) was performed using a set of atmospheric parameters. As the experiments duration was about $20 \mathrm{~min}$, we used our mean experimental values. Thus, wind velocity, shortwave radiation, cloudiness index, atmospheric pressure, and humidity were set at the following constant values: $2 \mathrm{~m} / \mathrm{s}, 200 \mathrm{~W} / \mathrm{m}^{2}, 0.5,1,013 \mathrm{hPa}$, and $60 \%$, respectively. In an attempt to limit sensible heat exchanges, the initial temperature along the flume, as well as the upstream thermal boundary conditions and the air temperature, was all set to $15^{\circ} \mathrm{C}$. Manning and dispersion coefficients were indexed on the previous experimental calibration (i.e., $0.012 \mathrm{~s} / \mathrm{m}^{1 / 3}$ and $0.025 \mathrm{~m}^{2} / \mathrm{s}$, respectively).

Additional simulations were performed to explore effects of flume water volume and upstream energy loss on mean thermal anomalies corrected for atmospheric exchanges $A_{\operatorname{sim}}{ }^{{ }^{-a}}$ under laminar flow conditions. First, simulations were performed without a weir at the end of the flume (water stage $=2 \mathrm{~cm}$ instead of $\geq 20 \mathrm{~cm}$ ). A water stage of $2 \mathrm{~cm}$ as a boundary condition yielded a Reynolds number of circa 1774, indicating transitory flow instead of net laminar flow conditions. The $A_{\operatorname{sim}}{ }^{{ }^{*-a}}$ of these simulations were then corrected by adding the energy dispersed upstream of the injection point (Figures $3 \mathrm{~d}$ and $5 \mathrm{~d}$ ). To estimate this energy loss, the quantity of heat upstream of the injection $\mathrm{E}_{\text {up }}$ was calculated as the sum of temperatures in this section at steady state. $\mathrm{E}_{\mathrm{up}}$ was then compared to the quantity of heat downstream of the injection point $\mathrm{E}_{\mathrm{dn}}$. The ratio $\mathrm{E}_{\mathrm{up}}: \mathrm{E}_{\mathrm{dn}}$ was used to estimate the energy loss, which ranged from $14.7 \%(P=33 \%)$ to $15.0 \%(P=4 \%)$.

\subsection{Data Processing}

The mean thermal anomaly $A$ caused by the warm inflow was quantified using the same approach for experiments and simulations (Figure 2). Since the experiments were 3-D, experimental data from the six sections of fiber-optic cable (Figure 1) were averaged into a single data set before the quantification itself. The data were averaged because small thermal differences were observed between each section of cable under turbulent flow (mean standard deviation $\left.\mathrm{SD}=0.07^{\circ} \mathrm{C}\right)$. Under laminar flow, the mean $\mathrm{SD}$ for the six sections of cable was slightly higher $\left(0.13^{\circ} \mathrm{C}\right)$ because the shallower data $\left(\mathrm{SD}=0.09^{\circ} \mathrm{C}\right.$ excluding the data at $\left.19 \mathrm{~cm}\right)$ was influenced by direct solar radiation on the black cable (Neilson et al., 2010). For each experiment, however, the SD remained smaller than the uncertainty in the FO-DTS measurements (Table 1, RMSE), making it difficult to assess any stratification. For all these reasons, we assumed that the mixing was good and the stratification limited enough to allow the data to be averaged into a single data set. Averaging the experimental data also simplified comparison of experiments and simulations.

To convert temperature into increases in temperature (i.e., thermal anomalies $T^{*}$ ), first, for both experiments and simulations, at each time step, the temperature along the flume was scaled as below:

$$
\boldsymbol{A}^{*}=\frac{\boldsymbol{A}}{\Delta \boldsymbol{T}}
$$

$$
\text { where } \Delta T=T_{g w}-T_{u p}
$$

Second, we quantified the mean thermal anomaly $A$ caused by the warm inflow by averaging the $T^{*}$ signal in a spatiotemporal window of interest (Figure 2). In space, this window was $1 \mathrm{~m}$ long and located 1 $\mathrm{m}$ downstream from the injection point. This location in the first part of the flume was chosen to prevent 

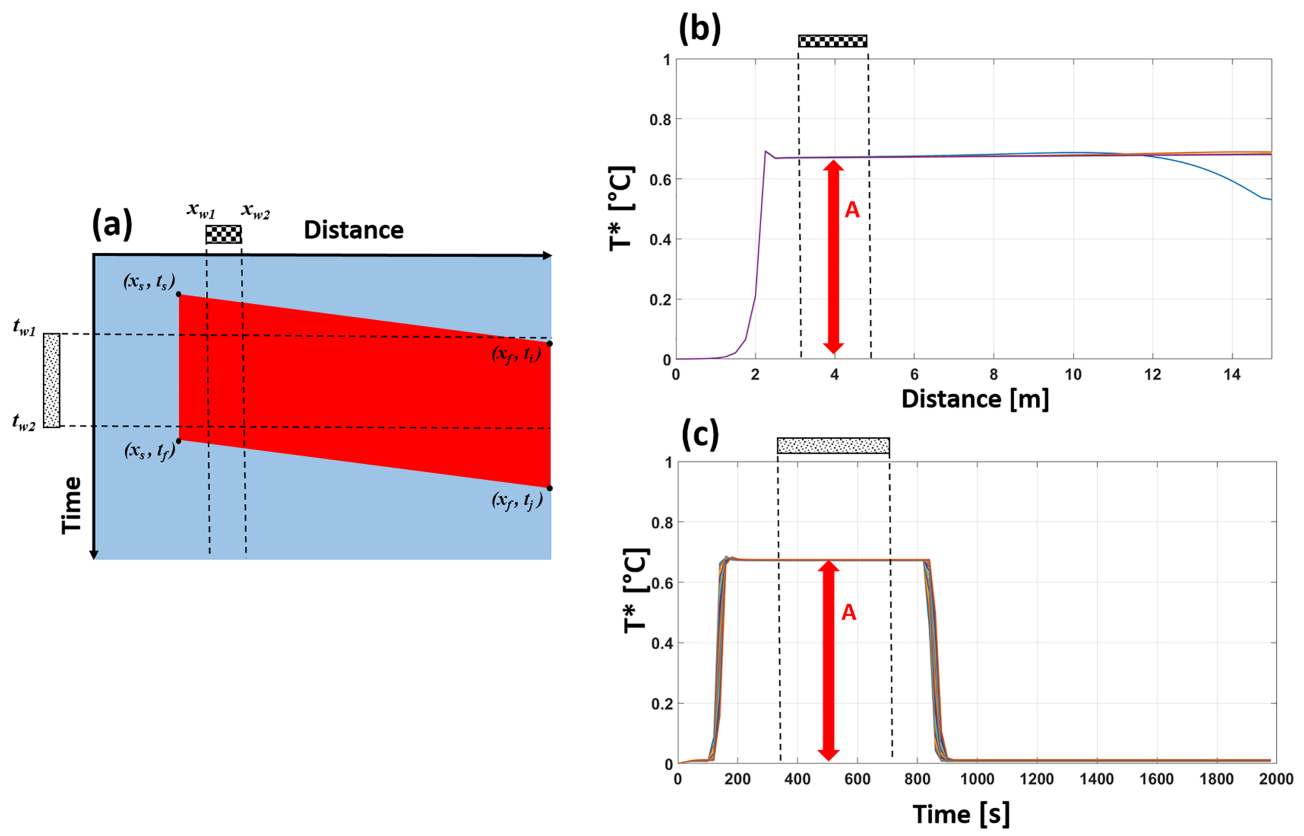

Figure 2. Conceptual diagram of the data processing method. (a) Diagram of the spatiotemporal data obtained using the FO-DTS system with starting $\left(x_{s}, t_{s}\right)$ and ending $\left(x_{s}, t_{f}\right)$ injection points. A spatiotemporal window of interest delimited by a spatial range $\left[x_{w 1}: x_{w 2}\right]$ and a temporal range $\left[t_{w 1}: t_{w 2}\right]$ is determined. (b) Scaled temperature-or thermal anomaly $T^{*}$ -along the flume within the temporal window of interest $\left[t_{w 1}: t_{w 2}\right]$. The dashed lines show the spatial window $\left[x_{\mathrm{w} 1}: x_{\mathrm{w} 2}\right]$ from which the mean thermal anomaly $A$ is calculated. (c) Temporal evolution of thermal anomalies between the two cross sections of interest $\left[x_{w 1}: x_{w 2}\right]$. The dashed lines represent the temporal window $\left[t_{w 1}: t_{w 2}\right]$ from which the thermal anomaly $A$ is calculated.

effects of atmospheric warming along the flume length (Figure 3). This spatial window was the same for both experiments and simulations. In time, the window was set to last $3 \mathrm{~min}$ for both experiments and simulations. Since experimental injections were short due to equipment limitations, the temporal window covered the last $3 \mathrm{~min}$ before the end of injection to ensure that the anomaly calculated was as close as possible to steady-state flow conditions. Ultimately, temporal windows for experiments varied, some starting earlier $(Q=3.6 \mathrm{~L} / \mathrm{s})$ than others $(Q=0.8 \mathrm{~L} / \mathrm{s})$ depending on the injection duration. In simulations, the temporal window was set to wait for a steady state and was thus extended from 87-90 min after the injection started. Mean thermal anomalies obtained through experiment or simulation were named $A_{\text {exp }}$ and $A_{\text {sim }}$, respectively. The thermal contrast $\Delta T$ between injected water and flume water fluctuated during the experiments, and different contrasts were tested during simulations. Therefore, to compare all of the results efficiently, we normalized the mean thermal anomalies $A$ by dividing them by their respective $\Delta T$. These normalized mean thermal anomalies were superscripted $A_{\text {exp }}{ }^{*}$ and $A_{\text {sim }}{ }^{*}$.

Once our data were processed, we compared them using the most commonly used model in the literature, which assumes perfect mixing and does not consider significant heat exchanges other than mass transfer. This reference model was based upon the following heat balance equation of Selker, van de Giesen, et al. (2006):

$$
Q_{T} \cdot T_{d n}=Q \cdot T_{u p}+q \cdot T_{i n j}
$$

where, respectively, $Q_{T}$ and $T_{d n}$ are the total discharge $\left(\mathrm{m}^{3} / \mathrm{s}\right)$ and water temperature $\left({ }^{\circ} \mathrm{C}\right)$ downstream of the groundwater inflow, $Q$ and $T_{u p}$ are the discharge and temperature upstream of the inflow, and $q$ and $T_{i n j}$ are the discharge and temperature of the injected inflow itself. Flume discharge $Q$ was measured using the Parshall system located upstream of the flume experiment, and the injection flow rate $q$ was set using the pump. Considering the inflow percentage $P=\frac{q}{Q_{T}} \times 100$ and the thermal contrast $\Delta T=T_{i n j}-T_{u p}$, equation (6) can be modified to obtain a theoretical thermal anomaly $A_{t}$ as a function of both $P$ and $\Delta T$ : 

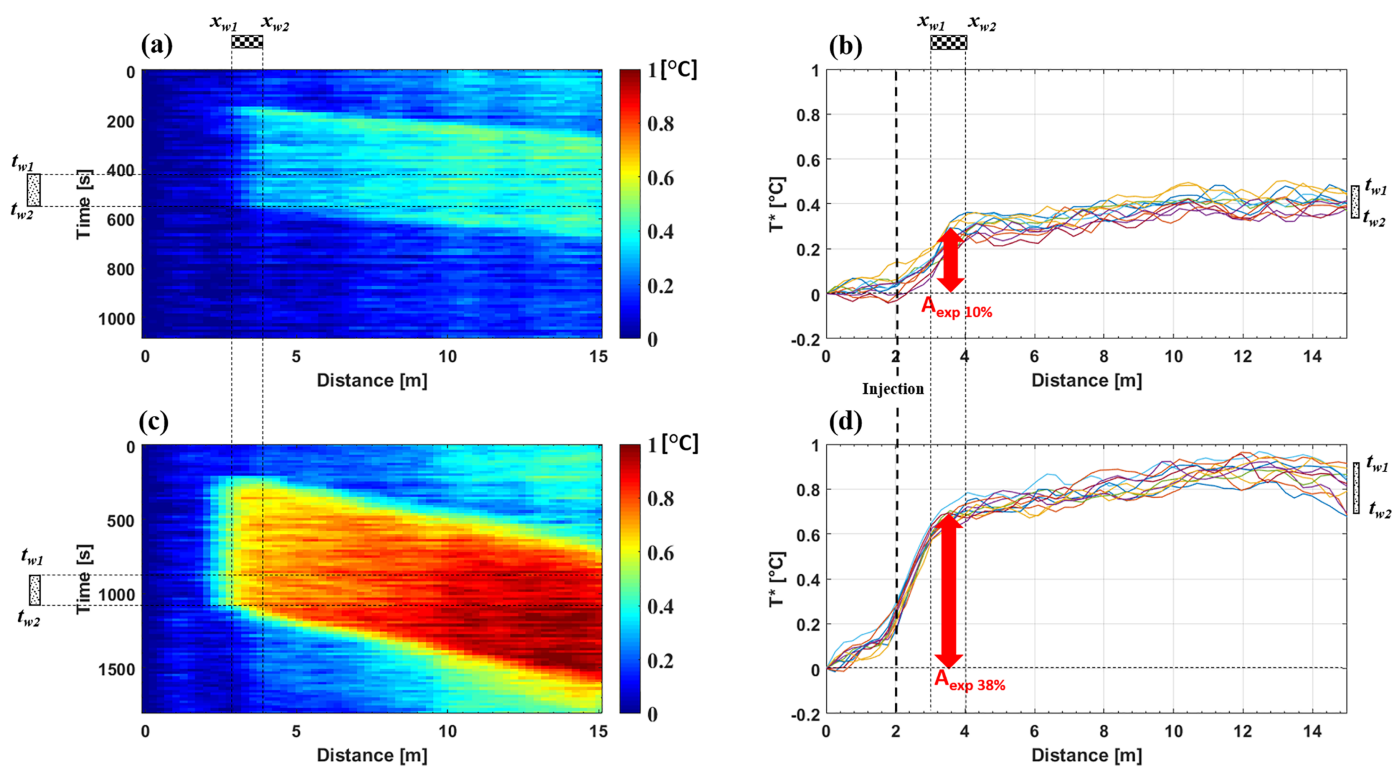

Figure 3. Spatiotemporal evolution of thermal anomalies $T^{*}$ along the hydraulic flume ( $x$ axis) and over time ( $y$ axis) for (a) $Q=3.6 \mathrm{~L} / \mathrm{s}, P=10 \%$ and (c) $Q=0.8 \mathrm{~L} / \mathrm{s}, P=38 \%$. The spatiotemporal window in which the mean thermal anomaly $A_{\text {exp }}$ was measured was located at the intersection of the vertical and horizontal dotted lines (i.e., $\left.\left[x_{w 1}: x_{w 2} ; t_{w 1}: t_{w 2}\right]\right)$. Thermal anomalies $T^{*}$ along the flume highlights the mean thermal anomaly $A_{\exp }$ due to the warm injection for (b) $Q=3.6 \mathrm{~L} / \mathrm{s}, P=10 \%$ and (d) $Q=0.8 \mathrm{~L} / \mathrm{s}, P=38 \%$. Plots are scaled to the upstream temperature to highlight the temperature increase as a function of distance (thermal anomaly).

$$
A_{t}=T_{d n}-T_{u p}=\frac{P . \Delta T}{100}
$$

In the following results, $A_{t}$ as a function of $P$ was used as the reference to which the experimental and simulated thermal anomalies $A_{\exp }{ }^{*}$ and $A_{\text {sim }}{ }^{*}$ were compared. To compare it to these normalized data, $A_{t}$ was obtained by setting $\Delta T=1{ }^{\circ} \mathrm{C}$.

Finally, following equations (6) and (7), the thermal anomaly can be compared to a two-component mixing model (Selker, van de Giesen, et al., 2006). Thus, the uncertainty in $A_{\text {exp }}{ }^{*}$ was calculated following the theory of propagation of errors of Genereux (1998) developed for such models:

$$
\mathrm{W}_{\mathrm{A}_{\text {exp }}^{*}}=\sqrt{\left[\frac{\mathrm{T}_{\text {dn }}-\mathrm{T}_{\text {up }}}{\left(\mathrm{T}_{\text {inj }}-\mathrm{T}_{\text {up }}\right)^{2}} \cdot \mathrm{W}_{\mathrm{T}_{\text {up }}}\right]^{2}+\left[\frac{\mathrm{T}_{\mathrm{dn}}-\mathrm{T}_{\text {up }}}{\left(\mathrm{T}_{\text {inj }}-\mathrm{T}_{\text {up }}\right)^{2}} \cdot \mathrm{W}_{\mathrm{T}_{\text {inj }}}\right]^{2}+\left[\frac{-1}{\left(\mathrm{~T}_{\text {inj }}-\mathrm{T}_{\text {up }}\right)^{2}} \cdot \mathrm{W}_{\mathrm{T}_{\mathrm{dn}}}\right]^{2}=\sqrt{\left[\frac{\mathrm{T}_{\mathrm{dn}}-\mathrm{T}_{\text {up }}}{\Delta \mathrm{T}^{2}} \cdot \mathrm{W}_{\mathrm{T}_{\text {up }}}\right]^{2}+\left[\frac{\mathrm{A}_{\text {exp }}^{*}}{\Delta \mathrm{T}^{2}} \cdot \mathrm{W}_{\mathrm{T}_{\text {inj }}}\right]^{2}+\left[\frac{-1}{\Delta \mathrm{T}} \cdot \mathrm{W}_{\mathrm{T}_{\text {dn }}}\right]^{2}}}
$$

where $W_{A_{\text {exp }}^{*}}$ is the propagated error of the normalized experimental thermal anomaly $A_{\text {exp }}{ }^{*} \cdot W_{T_{u p}}, W_{T_{d n}}$, and $W_{T_{i n j}}$ are measurement uncertainties in temperatures of the upstream flume, downstream flume, and tank water, respectively. $W_{T_{i n j}}$ was set to the accuracy of the RBRsolo logger $\left(0.002{ }^{\circ} \mathrm{C}\right)$ in the warm water tank. $W_{T_{u p}}$ and $W_{T_{d n}}$ were set to the RMSE calculated for each experiment (Table 1). The final propagated error was used to set the error bars visible in figures displaying the experimental results.

\section{Results}

\subsection{Hydraulic Properties of Experiments and Simulations}

Hydraulic characteristics of the experiments and simulations varied as a function of flume geometry and $Q$ (Table 2). The Reynolds numbers revealed two distinct flow regimes in both the experiments and simulations. Each flume discharge $Q \geq 3.6 \mathrm{~L} / \mathrm{s}$ had a Reynolds number $R e \geq, 3300$, indicating turbulent flow. When $Q \leq 1 \mathrm{~L} / \mathrm{s}$, however, Reynolds numbers were less than 1,000, clearly indicating laminar flow for one half of the experiments and one fifth of the 90 simulations. Simultaneously, with Peclet numbers that 
Table 2

Hydraulic Characteristics of the Experiments and Simulations Upstream of the Injection Point

\begin{tabular}{|c|c|c|c|c|c|c|c|c|c|}
\hline & $\begin{array}{l}\text { Discharge } \\
Q(\mathrm{~L} / \mathrm{s})\end{array}$ & $\begin{array}{l}\text { Water } \\
\text { stage } \\
(\mathrm{m})\end{array}$ & $\begin{array}{l}\text { Cross } \\
\text { section } \\
\left(\mathrm{m}^{2}\right)\end{array}$ & $\begin{array}{l}\text { Hydraulic } \\
\text { radius (m) }\end{array}$ & $\begin{array}{l}\text { Wetted } \\
\text { width } \\
(\mathrm{m})\end{array}$ & $\begin{array}{l}\text { Velocity } \\
(\mathrm{m} / \mathrm{s})\end{array}$ & $\begin{array}{l}\text { Reynolds } \\
(-)\end{array}$ & $\begin{array}{l}\text { Peclet } \\
(-)\end{array}$ & $\begin{array}{l}\text { Froude } \\
(-)\end{array}$ \\
\hline \multirow[t]{2}{*}{ Experiments } & 0.8 & 0.211 & 0.115 & 0.126 & 0.547 & 0.00694 & 767 & 6 & 0.0048 \\
\hline & 3.6 & 0.225 & 0.125 & 0.132 & 0.553 & 0.02893 & 3,301 & 26 & 0.0195 \\
\hline \multirow[t]{5}{*}{ Simulations } & 1 & 0.22 & 0.121 & 0.130 & 0.551 & 0.00825 & 938 & 7 & 0.0056 \\
\hline & 5 & 0.23 & 0.128 & 0.134 & 0.555 & 0.03914 & 4,584 & 36 & 0.0261 \\
\hline & 10 & 0.25 & 0.141 & 0.141 & 0.565 & 0.07085 & 8,765 & 70 & 0.0452 \\
\hline & 20 & 0.28 & 0.162 & 0.152 & 0.578 & 0.12351 & 16,445 & 131 & 0.0745 \\
\hline & 30 & 0.3 & 0.176 & 0.159 & 0.587 & 0.17022 & 23,689 & 188 & 0.0992 \\
\hline
\end{tabular}

Note. Experimental discharges were measured using the Parshall system. Water stages were measured $2 \mathrm{~m}$ downstream of the injection for the experiments and extracted from the flume-gauging curve for the simulations. Velocity in the experiments was calculated from discharge and wet area. Velocity in the simulations was obtained from model outputs.

ranged from 6-188, advection was more common than diffusion for all of the experiments and simulations (Table 2). Likewise, with Froude numbers of 0.0047-0.0992, all of the experiments and simulations had a fluvial regime (i.e., subcritical flow).

\subsection{Experimental Relationship Between the Thermal Anomaly and Inflow Percentage}

Focusing on two experiments with different flume discharges $(Q=3.6$ and $0.8 \mathrm{~L} / \mathrm{s})$, and thus different flow regimes, as an example, their results showed contrasting inflow percentages $(P=10 \%$ and 38\%, respectively) and thermal contrasts between the flume and injected waters $\left(\Delta T=3.4\right.$ and $2.8{ }^{\circ} \mathrm{C}$, respectively) (Figure 3). Scaled temperature behavior also differed among experiments as a function of flume discharge and inflow percentage. Under turbulent flow $(Q=3.6 \mathrm{~L} / \mathrm{s}$ and $P=10 \%)$, thermal anomaly stabilized relatively close to the injection point ( $1 \mathrm{~m}$ downstream of it) (Figure $3 \mathrm{~b}$ ). Progressive warming with distance ( $+0.1^{\circ} \mathrm{C}$ along the next $\left.11 \mathrm{~m}\right)$. Under laminar flow $(Q=0.8 \mathrm{~L} / \mathrm{s}$ and $P=38 \%)$, thermal anomaly caused by the injection stabilized at approximately the same distance $(3 \mathrm{~m})$ as that for turbulent flow (Figure 3d). However, atmospheric warming with distance was greater $\left(+0.18{ }^{\circ} \mathrm{C}\right)$, and the thermal anomaly also extended upstream of the injection point $(1 \mathrm{~m}$ ). The patterns for $Q=3.6 \mathrm{~L} / \mathrm{s}$ and $P=10 \%$ (Figures $3 \mathrm{a}$ and $3 \mathrm{~b}$ ) were also observed for the other experiments under turbulent flow conditions, while the patterns for $Q=0.8 \mathrm{~L} / \mathrm{s}$ and $P=38 \%$ (Figures $3 \mathrm{c}$ and $3 \mathrm{~d}$ ) were present to varying degrees for the other experiments under laminar flow conditions.

\subsection{Model Calibration}

In the experiments, $A_{\text {exp }} *$ increased with $P$, with no clear difference between $A_{\text {exp }}$ obtained under turbulent or laminar flow conditions (Figure 4a). For simulations of the experiments with $P=8 \%, 10 \%, 38 \%$, and $41 \%$, the differences in mean thermal anomaly $A^{*}$ between simulations and experiments were $0.015,0.017,0.024$, and $0.04{ }^{\circ} \mathrm{C}$, respectively. All of the simulated temperatures lay within the uncertainty of the experimental thermal anomaly (ranging from \pm 0.048 to \pm 0.088 ; equation (8)). For $P=10 \%(Q=3.6 \mathrm{~L} / \mathrm{s}$; turbulent flow), the warm plume reached the end of the flume somewhat faster in the simulation than in the experiment (Figures $4 \mathrm{~b}$ and $4 \mathrm{c}$ ). Similarly, heat accumulation downstream of the flume was higher in the simulation than in the experiment. The differences between simulations and experiments were about $0.03{ }^{\circ} \mathrm{C}$, small enough to be considered negligible. Therefore, the model was considered valid for our purposes.

\subsection{Simulated Thermal Anomaly as a Function of Distance and Time}

In the simulations, under turbulent flow conditions, $T^{*}$ peaked almost immediately ( $20 \mathrm{~s}$ after the injection) and reached the end of the flume in $\sim 80 \mathrm{~s}$, indicating a steady state (Figure 5a). The amplitude of $T^{*}$ was $\sim 0.18,0.68$, and $1.34{ }^{\circ} \mathrm{C}$ for $\Delta T=0.5,2$, and $4{ }^{\circ} \mathrm{C}$, respectively. Examination of $T^{*}$ as a function of distance revealed the same values, with the thermal anomaly appearing within $0.25 \mathrm{~m}$ downstream of the injection point (Figure 5b). Once the plume reached the end of the flume, the temperature remained constant. These simulation results echoed those of the experiment with $Q=3.6 \mathrm{~L} / \mathrm{s}$ and $P=10 \%$ (Figure $3 \mathrm{~b}$ ). 
(a)
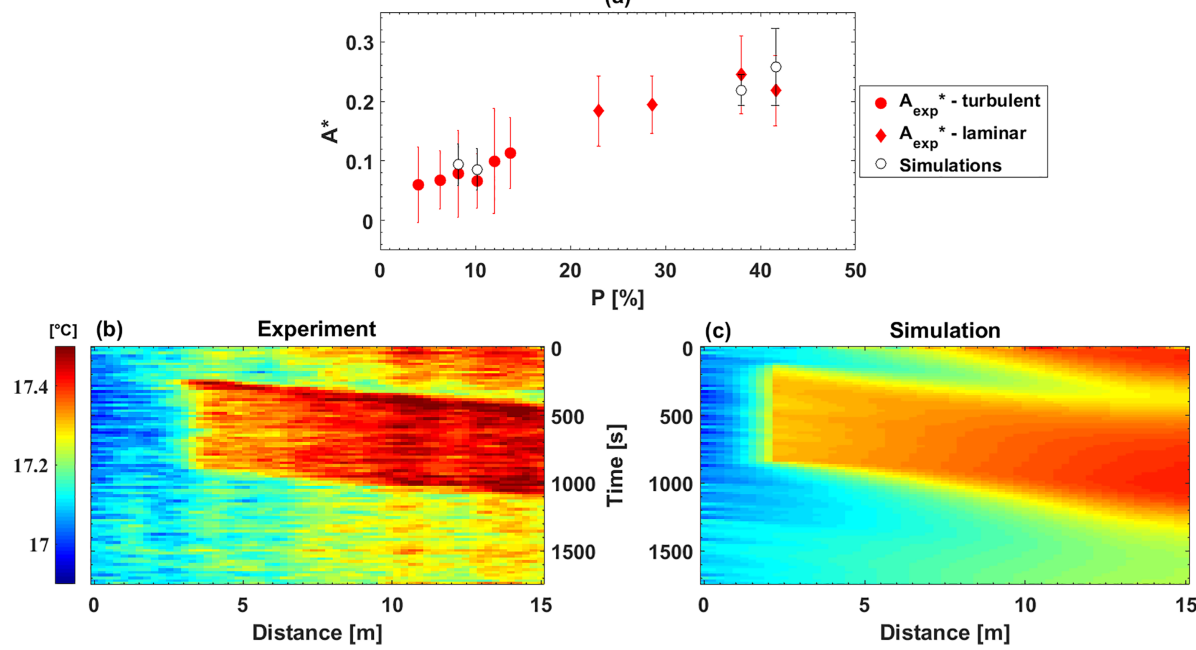

Figure 4. Calibration of the 1-D model with experimental data. (a) Normalized thermal anomalies from experiments $\left(A_{\exp }{ }^{*}\right)$ and their simulated counterparts as a function of inflow percentage $P$. The red error bars were set according to equation (8). White circles are mean simulated thermal anomalies predicted by the model, using thermal data from four experiments as boundary conditions. Black error bars are standard deviations of the spatiotemporal window used to calculate the simulated thermal anomaly (see Figure 2). (b) Two-dimensional map of temperature evolution during the injection experiment $(Q=3.6 \mathrm{~L} / \mathrm{s}, P=10 \%)$. (c) Two-dimensional map of temperature evolution during the simulation using data from the same experiment $(Q=3.6 \mathrm{~L} / \mathrm{s}, P=10 \%)$ as boundary conditions.

Under laminar flow conditions, $T^{*} 1 \mathrm{~m}$ downstream of the injection point increased progressively over time and attained a steady state at $\sim 1,500 \mathrm{~s}$ (Figure $5 \mathrm{c}$ ). The increase in $T^{*}$ at the end of the flume was slower, starting later and reaching a steady state later, at $\sim 2,500 \mathrm{~s}$. At $1 \mathrm{~m}$ downstream of the injection point, the amplitude of $T^{*}$ was $\sim 0.14,0.43$, and $0.81^{\circ} \mathrm{C}$ for $\Delta T=0.5,2$, and $4{ }^{\circ} \mathrm{C}$, respectively. Examination of $T^{*}$ as a function of distance revealed that, $40 \mathrm{~s}$ after the start of the injection, the thermal anomaly spread out almost symmetrically both upstream and downstream, with a peak $0.25 \mathrm{~m}$ downstream of the injection point (Figure $5 \mathrm{~d}$ ). At the end of the injection (90 min), the anomaly increased in both directions but plateaued downstream, with only a slight increase with distance. This increase of temperature with distance in the experiments (Figure 3d) was observed with a lower increase $\left(+0.10^{\circ} \mathrm{C}\right.$ in simulations vs. $+0.18^{\circ} \mathrm{C}$ in experiments $)$ and did not vary with $\Delta T$.

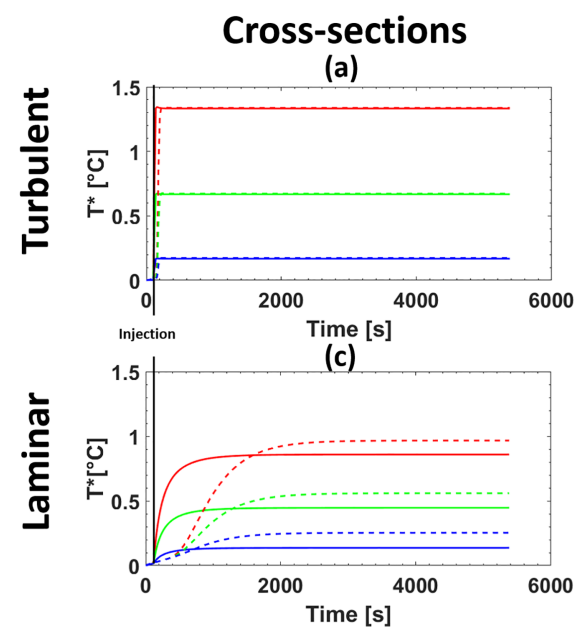

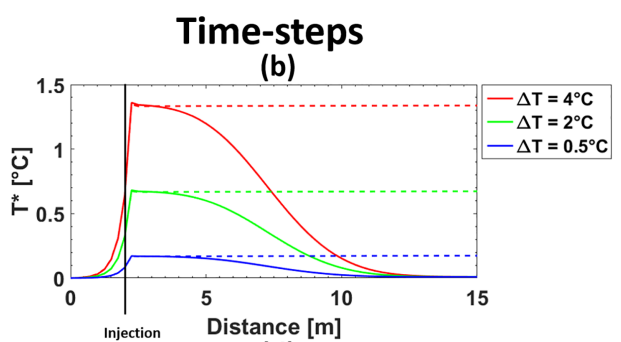

(d)

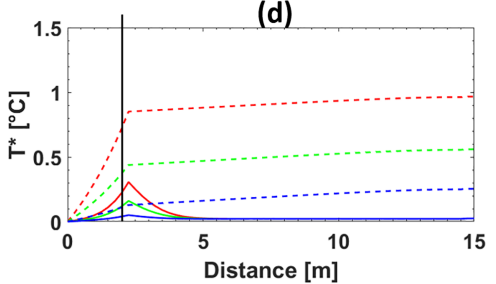

Figure 5. Simulated evolution in the thermal anomaly $\left(T^{*}\right)$ along the flume for inflow percentage $P=33 \%$ and for three $\Delta T$. Left-side graphs show $T^{*}$ over time $1 \mathrm{~m}$ downstream of the injection point (solid lines) and at the last cross section at the most downstream side of the flow domain (dashed lines), respectively under (a) turbulent or (c) laminar flow conditions. Right-side graphs show $T^{*}$ as a function of distance under (b) turbulent or (d) laminar flow conditions at two time steps: $40 \mathrm{~s}$ after injection (solid lines) and $90 \mathrm{~min}$ after injection (dashed lines). 
(a)
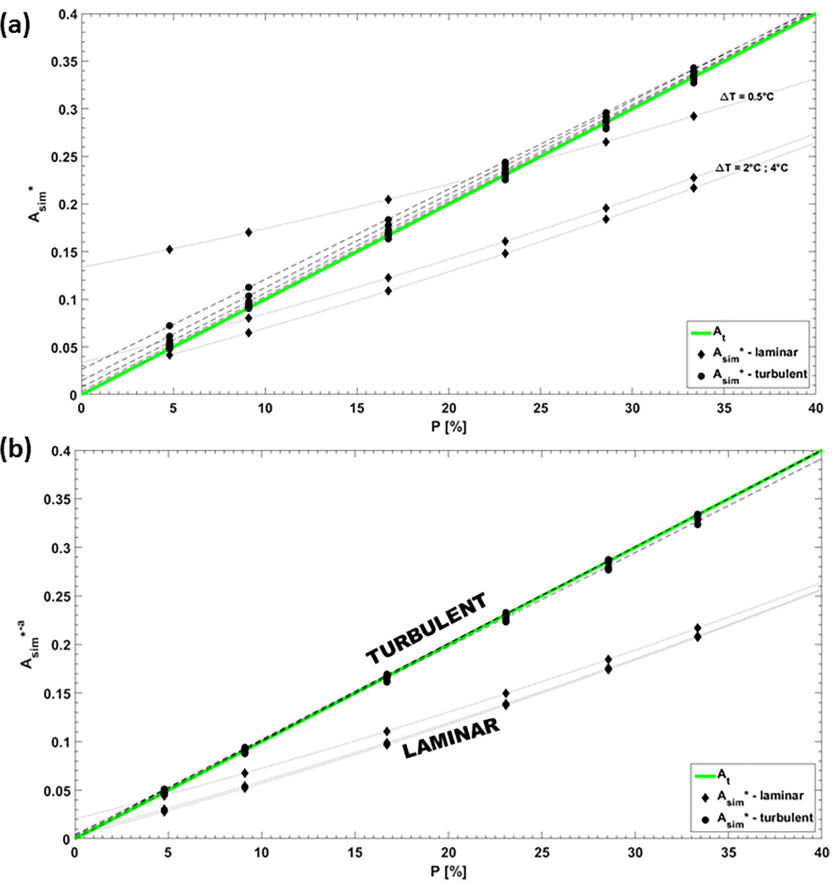

Figure 6. The (a) normalized simulated anomaly $A_{\text {sim }}{ }^{*}$ and (b) the same anomaly corrected for atmospheric exchanges $A_{\text {sim }}{ }^{*-a}$ (equation (2)) as a function of the inflow percentage $P$. The green line denotes the theoretical thermal anomaly $A_{t}{ }^{*}$ for $\Delta T=1{ }^{\circ} \mathrm{C}$ (equation (7)). Black dashed lines (bold $=$ turbulent regime; thin $=$ laminar regime) are the fit for all simulations and for each $\Delta T\left(0.5,2\right.$, or $\left.4{ }^{\circ} \mathrm{C}\right)$.
3.5. Simulation Results: Evolution in Thermal Anomaly Amplitude as a Function of Inflow Percentage, Thermal Contrast, and Flow Regime

In simulations, following equation (7), $A_{t}$ increased linearly with $P$ (slope of $1 \%$ ) (Figure 6a). Under turbulent flow conditions, the mean thermal anomaly $A_{\text {sim }}{ }^{*}$ followed a similar linear progression, with little differences between $A_{\text {sim }}{ }^{*}$ and $A_{t}$ (ranging from 0.013 to 0.040 for $P=4 \%$ and $33 \%$, respectively). Under laminar flow conditions, $A_{\text {sim }}{ }^{*}$ for $\Delta T=2$ and $4{ }^{\circ} \mathrm{C}$ increased more slowly with $P$ than that under turbulent flow while following a power law. The differences between $A_{\text {sim }}{ }^{*}$ and $A_{t}$ ranged from 0 to 0.12 for $P=5 \%$ and $33 \%$, respectively. $A_{\text {sim }}{ }^{*}$ for $\Delta T=0.5^{\circ} \mathrm{C}$ displayed a similar increase with $P$ but with much higher values at lower percentages: $0.14{ }^{\circ} \mathrm{C}$ for $P=5 \%$ versus $0.03-0.07{ }^{\circ} \mathrm{C}$ for all other simulations and experiments.

This peculiar behavior was suspected to be due to atmospheric exchanges (equation (3)). To verify this hypothesis, simulation results were corrected $\left(A_{\text {sim }}{ }^{*-a}\right)$ by subtracting atmospheric heat influx from $A_{\text {sim }}$ before normalization by $\Delta T$. According to simulations, the net influx $q_{\text {net }}$ (equation (2)) was $\sim 115 \mathrm{~W} / \mathrm{m}^{2}$. Following equation (1) adapted to a flume length of $3.5 \mathrm{~m}$ (distance between the measurement window and the upstream reference), the atmospheric heat source term $H$ ranged from 0.00012 to $0.00009{ }^{\circ} \mathrm{C} / \mathrm{s}$ for $Q=1$ and $30 \mathrm{~L} / \mathrm{s}$, respectively (see surface width in Table 2). Once multiplied by the time necessary to drain the volume of this $3.5 \mathrm{~m}$ long section for each simulation (see velocity in Table 2), thermal corrective values ranged from $0.0013{ }^{\circ} \mathrm{C}(Q=30 \mathrm{~L} / \mathrm{s} ; P=33 \%)$ to 0.0505 ${ }^{\circ} \mathrm{C}(Q=1 \mathrm{~L} / \mathrm{s} ; P=5 \%)$. Under turbulent flow, $A_{\operatorname{sim}}{ }^{*^{-a}}$ lay closer to theoretical values than $A_{\text {sim }}{ }^{*}$ (Figure 6b). Under laminar flow, $A_{\text {sim }}{ }^{{ }^{-a}}$ increased with $P$ almost identically for all three values of $\Delta T$ but was lower than $A_{\text {sim }}{ }^{*-a}$ under turbulent flow (Figure 6b).

When simulating no weir, $A_{\text {sim }}{ }^{*-a}$ under turbulent flow were identical to $A_{t}$ (like those with a weir; Figure 6b). Under laminar flow nonweir $A_{\text {sim }}{ }^{*-a}$ were lower than $A_{t}$ but higher than those with a weir (Figure 7). For instance, for $P=9 \%$ and 33\%, the nonweir $A_{\text {sim }}{ }^{*-a}$ was only 0.015 and $0.3{ }^{\circ} \mathrm{C}$ lower than $A_{t}$, respectively (17\% and $10 \%$ error, respectively). When the nonweir anomalies were corrected for the energy dispersed upstream, they appeared almost identical to the theoretical $A_{t}$ (Figure 7). For low $P$, nonweir loss-corrected $A_{\text {sim }}{ }^{*-a}$ were similar to $A_{t}$, while that for $P=33 \%$ was only $0.01{ }^{\circ} \mathrm{C}$ higher than $A t$ ( $0.3 \%$ error). The error between corrected $A_{\text {sim }}{ }^{*-a}$ and $A_{t}$ increased with $P$.

When plotting these simulated and theoretical mean thermal anomalies with the experimental flume data (Figure 3a) and experimental field data from Lauer et al. (2013), $A_{\text {sim }}{ }^{{ }^{-a}}$ for $P=2-12 \%$ generally followed the same trend as $A_{t}$, with slightly (but consistently) lower values (Figure $\mathrm{S} 1$ in the supporting information).

\section{Discussion}

\subsection{Compatibility Between Simulations and Experiments}

Properly conducting experiments that successfully mimicked a point-source injection of groundwater was difficult, since many external factors interfered with measurements. Obtaining a stable flow regime within the flume during some of the experiments was sometimes challenging, especially for experiments with laminar flow $(Q=0.8 \mathrm{~L} / \mathrm{s})$, because of the moving gate valve upstream. This somewhat imprecise experimental $Q$ affected the estimation of the inflow percentage $P$ and could explain some differences between experiments and simulations. Unfortunately, the uncertainty in these discharge measurements was difficult to estimate because of the lack of reference measurements at the time. However, field results of Lauer et al. (2013) for turbulent flow - transitory discharge, different thermal anomalies and low inflow percentages-were similar to ours (supporting information). 


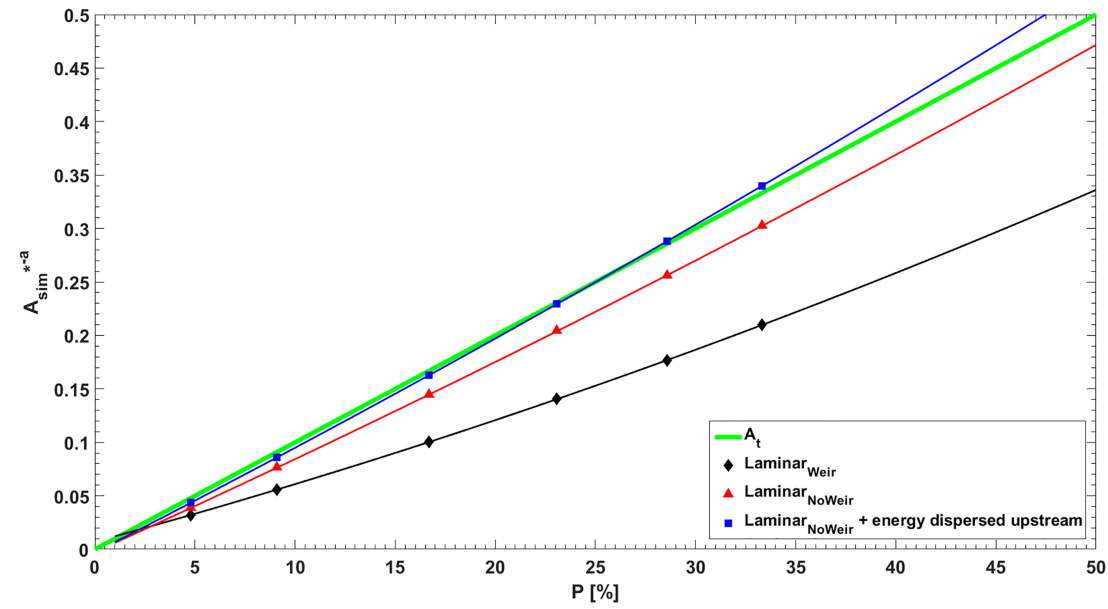

Figure 7. The simulated anomaly $A_{\text {sim }^{*}}{ }^{-\mathrm{a}}$ as a function of the inflow percentage $P$ under laminar flow conditions $\left(\Delta T=2{ }^{\circ} \mathrm{C}\right)$ with a weir (Figure $\left.6 \mathrm{~b}\right)$, without a weir (stage $=2 \mathrm{~cm}$ ) and without a weir and corrected for the thermal energy dispersed upstream of the injection point (Figure $5 \mathrm{~d}$ ). The green denotes the theoretical thermal anomaly $A_{t}$ for $\Delta T=1{ }^{\circ} \mathrm{C}$ (equation (7))

Apart from the hydraulics management, the large temperature difference between the water and the air at times and the sunny conditions may progressively warmed the flume water with distance (Figure 3). This warming was the main reason that we chose a measurement window only $1 \mathrm{~m}$ downstream of the injection point. However, direct solar radiation on fiber optics is known to influence FO-DTS measurements (Neilson et al., 2010). While some heating was observed at heights of $19 \mathrm{~cm}$ (just below the water surface) under laminar flow, its influence on mean flume temperature did not decrease the acceptability of the accuracy of the FO-DTS system. Such artificial heating of shallow cables should have increased the mean thermal anomaly $A_{\text {exp }}{ }^{*}$ under laminar flow conditions, but these $A_{\exp }{ }^{*}$ remained lower than theoretical anomalies under turbulent flow conditions (Figure 6 and supporting information). Therefore, although solar radiation may have influenced measurements in this study, we considered its influence to be negligible.

Another experimental issue was the thermal contrast $\Delta T$ between injected water and flume water measured during the experiments and used to normalize the mean thermal anomalies $A_{\text {exp }}$. Since the injected water first traveled through a hose that was exposed to solar radiation and then submerged under water before the actual injection, it was difficult to determine the true value of $\Delta T$. Heating the water in the hose before injecting it occasionally caused larger anomalies at the beginning of the injection (e.g., Figure 3a). On the other hand, the submerged section of the hose probably decreased the temperature of the injection water before injection, which could explain why $A_{\text {exp }}{ }^{*}$ were lower than their simulated counterparts $A_{\text {sim }}{ }^{*}$ (Figure 4a). By modifying the experimental $\Delta T$ by less than a degree (from +0.3 to $-0.7^{\circ} \mathrm{C}$ ), $A_{\exp }{ }^{*}$ matched the simulations perfectly (data not shown, since we could not precisely quantify how much the thermal contrast $\Delta T$ had been modified in experiments). In the future, measuring the thermal contrast $\Delta T$ at the injection point itself and using an injection hose isolated from external influences (solar radiation and flume water) would be preferable.

The 1-D simulations were used to explore parameters controlling the thermal anomaly and ultimately to quantify their influences. As such, calibrating the model beforehand was central to this study. Since we focused on the normalized mean thermal anomaly $A^{*}$ just downstream of the injection point, we chose to use $A^{*}$ as a proxy of model quality. Model predictions matched experiments relatively well (Figure 4a), and as mentioned, differences between simulated and experimental $A^{*}$ can probably be explained by the approximate thermal contrast $\Delta T$ measured during experiments. Another explanation could be poor estimation of energy exchanges at the air-water interface. Indeed, all meteorological data used to calculate these exchanges-except for air temperature-came from a weather station $6 \mathrm{~km}$ away with only hourly measurements. This led to rough estimates of exchanges with the atmosphere. The relatively short length of our measurement window $(1 \mathrm{~m})$ for $A^{*}$, however, should have limited the impact of poor estimation of these exchanges. 
Use of $A^{*}$ alone as a proxy can obviously be questioned, since it does not consider longitudinal differences. For instance, the plume required more time to reach the end of the flume in simulations than in experiments (Figures $4 \mathrm{~b}$ and $4 \mathrm{c}$ ), especially under laminar flow conditions. This apparent slowness was first attributed to the low thermal dispersion coefficient $\left(d=0.025 \mathrm{~m}^{2} / \mathrm{s}\right)$ used in the model, but simulations with higher dispersion coefficients $\left(d>0.5 \mathrm{~m}^{2} / \mathrm{s}\right)$ yielded significantly lower thermal anomalies than those in experiments. Another potential explanation was nonconstant flume discharge during experiments, which had already caused the failure of two of the experiments. For instance, experiments with a nominal discharge of $0.8 \mathrm{~L} / \mathrm{s}$ might actually have had a slightly higher discharge, resulting in a transitory flow regime instead of a laminar flow regime. This could explain the faster propagation of the plume in experiments than in simulations.

In sum, comparison of simulated and experimental results relied mainly on $A^{*}$ as a proxy. Differences between them are suspected to have been due mainly to experimental limitations (discharge management) and a nonoptimized setup (variable thermal contrast $\Delta T$ and direct solar radiation), even though model parameters such as dispersion could be involved. Nonetheless, and despite the imperfect nature of the proxy chosen, simulation results were close to experimental results. Since we were interested in the thermal anomaly just upstream or, at most, immediately downstream of the injection point $(1 \mathrm{~m})$, the model was therefore considered valid. Future studies would gain from a more insulated experimental setup (e.g., indoors) and local meteorological measurements (e.g., shortwave and longwave radiation, wind speed, humidity, and cloudiness) to help refine the model. Considering energy exchanges with the bed (conduction) would also be useful.

\subsection{Thermal Anomaly Response to Turbulent Flow}

Given the similarity of the flume experiments' flow regime to a natural stream (i.e., turbulent subcritical flow), our results are compatible with the heat balance equation that assumes perfect mixing and no heat loss (equation (6)). This assumption is possible because of the very little distance considered between our measurements and the injection point, like other studies that used this quantifying method highlighted it (Briggs et al., 2012; Selker, van de Giesen, et al., 2006). The mean thermal anomaly increased linearly with $P$, which provides insight into whether a focused groundwater inflow can be detected by an FO-DTS system or not. Lauer et al. (2013) claimed to be able to detect an inflow as low as $2 \%$ of upstream discharge, with $\Delta T$ values that ranged from $1.2-4.2^{\circ} \mathrm{C}$. Our results provide similar claims, given the $\Delta T$ and accuracy of the FODTS involved. The relatively short integration time of our experiments resulted in a mean accuracy of $0.15^{\circ} \mathrm{C}$ (Table 1). This brought our detection threshold for turbulent flow to $P$ values of $\sim 15 \%, 8 \%$, and $<5 \%$ for $\Delta T=$ 1,2 , and $4{ }^{\circ} \mathrm{C}$ respectively (equation (7)). We therefore emphasize the great influence of $\Delta T$ on the amplitude of the thermal anomaly and its detection threshold: The warmer the injected water, the lower the threshold. Nonetheless, the uncertainty will be higher for thermal anomalies that are more similar to the accuracy of the FO-DTS (Lauer et al., 2013).

Consequently, for future field studies, it is important to (i) calculate the accuracy of the FO-DTS configuration to determine the minimum thermal anomaly that can be detected, (ii) measure $\Delta T$ on field, and (iii) determine the minimum $P$ value that can be expected based on the given accuracy (equation (7)). The uncertainty in this estimate of $P$ can be determined using the propagation of errors theory of Genereux (1998) (equation (8)). Nonetheless, the present discussion of detection thresholds holds only for clearly turbulent, advection-dominated flows.

\subsection{Thermal Anomaly Behavior Under Laminar Flow Conditions}

Under laminar flow conditions, $A_{\text {sim }}{ }^{*}$ behaved differently than they did under turbulent flow regimes. At a given $P, A_{\text {sim }}{ }^{*}$ for $\Delta T=2$ or $4{ }^{\circ} \mathrm{C}$ had lower amplitudes than those under turbulent flow conditions (Figure 6a). The odd results obtained for $\Delta T=0.5^{\circ} \mathrm{C}$ were considered to be due an atmospheric effect combined with normalization. Because of the slow velocities of laminar flow (Table 2), the atmosphere contributed more energy for $\Delta T=0.5{ }^{\circ} \mathrm{C}$ than for the higher $\Delta T$. This effect was less visible for high thermal contrast $\left(\Delta T=2\right.$ or $\left.4{ }^{\circ} \mathrm{C}\right)$ because the energy input by injection was relatively high and normalization smoothed the results. For low thermal contrast $\left(\Delta T=0.5{ }^{\circ} \mathrm{C}\right)$, however, the atmosphere's contribution was not diluted by the injection and was then doubled artificially by the normalization. For instance, for $P=5 \%, A_{\text {sim }}{ }^{*}$ equaled 0.144 , while it was $\sim 0.048$ for other simulations under laminar flow with higher $\Delta T$, resulting in a $200 \%$ error (Figure 6a). In this case, the atmospheric exchanges were clearly not 
negligible, so it was necessary to correct them (Figure 6b) for proper comparison. Nonetheless, once corrected, thermal anomalies under laminar flow appeared to remain lower than their turbulent-flow counterparts. Here, the usual model assuming perfect mixing and no heat loss $\left(A_{t}\right)$ tended to underestimate the $P$ of a measured thermal anomaly (e.g., $A_{\text {sim }}{ }^{*}=0.21$ for $P=33 \%$; Figure 6). The classic model would interpret this anomaly as an inflow of $21 \%$ instead, underestimating it by $36 \%$. We consider our results as relevant enough to open discussion and highlight initial estimates of the influence of the processes involved.

First, little evidences of stratification were found during experiments (see section 2) and that led us to choosing a 1-D model that matched experimental results quite well (Figure 4a). Thus, stratification cannot explain the lower anomalies under laminar flow. Note, however, that stratification might play a role in case of higher water stages or under stronger solar radiation.

For $P=33 \%$ and under laminar flow conditions, there was a net gain of $0.1{ }^{\circ} \mathrm{C}$ between the cross section $1 \mathrm{~m}$ downstream of the injection point and that at the end of the flume, $11 \mathrm{~m}$ downstream (Figure $5 \mathrm{c}$ ). This temperature increase was attributed to atmospheric input (equations (1) and (2)). As such, atmospheric exchanges cannot be ignored: The slower the flow, the more energy the atmosphere contributes to the water. This was demonstrated clearly when the thermal anomalies under laminar flow (Figure 6a) were higher than those after these exchanges were removed (Figure 6b). Thus, atmospheric exchanges in this study were clear heat inputs that can lead to overestimating the mean thermal anomaly, especially under laminar flow. Therefore, we rejected the atmospheric-exchange argument to explain the lower thermal anomalies under laminar flow conditions.

Two factors may explain the lower mean thermal anomalies under laminar flow conditions. The first is the relatively high water stage $(\geq 20 \mathrm{~cm})$ artificially imposed downstream by the weir. Without this obstacle, the discharge responsible for laminar flow $(Q=1 \mathrm{~L} / \mathrm{s})$ should lead to a water stage of $\sim 1-2 \mathrm{~cm}$ and thus a smaller total water volume for a given discharge. With a smaller flume volume for a given inflow volume, heat concentration downstream of the inflow should be higher (equation (3)). In other words, artificially increasing a volume (e.g., weir and dam) should dilute the injected thermal signal. Without a weir, $A_{\text {sim }}{ }^{*}$ for laminar flow was indeed higher and closer to theory (equation (7)) under turbulent flow (Figure 7). Even without this volumetric dilution, however, laminar $A_{\text {sim }}{ }^{*}$ still remained lower than turbulent $A_{\text {sim }}{ }^{*}$.

The other factor is the apparent dispersion of the thermal signal upstream of the injection point. Overall, Peclet numbers of experiments and simulations (Table 2) indicate that the flow was dominated by advection. However, Peclet numbers for the laminar experiments and simulations are quite low and could have allowed weak dispersive processes (equation (3)). In addition, the Froude numbers (Table 2) indicate that every experiment and simulation displayed subcritical flow, meaning that waves could propagate in every direction, including upstream. Indeed, the thermal anomaly spread both upstream and downstream after injection in simulations (Figure 5d). The same pattern upstream of the injection point was observed in experiments (Figure 3d), even if it was not as clear as in the simulations. In experiments, it is necessary to ensure that the thermal anomaly visible upstream is indeed due to energy dispersing upstream and not just an artifact caused by the spatial resolution of the FO-DTS (0.50-0.75 m) (Selker, Tyler, et al., 2014). Since the thermal anomaly spread further than $1 \mathrm{~m}$ (Figure 3d), we argue that it was indeed energy traveling upstream of the flume. When this energy upstream of the injection point was roughly estimated ( 15\% of the downstream energy) and artificially returned downstream, $A_{\text {sim }}{ }^{*}$ under laminar flow (Figure 7) appeared similar to the theoretical $A_{t}$. When the same correction was performed for $A_{\operatorname{sim}}{ }^{*}$ with a weir, the resulting $A_{\operatorname{sim}}{ }^{*}$ was indeed higher but not enough to match $A_{t}$ (data not shown).

Ultimately, we explain the lower mean thermal anomaly amplitude under laminar flow conditions using a combination of these two processes. First, because of the water stage imposed by the weir, the injected warm water was diluted in a proportionally larger volume under laminar flow than under turbulent flow. Second, subcritical flow allowed dispersion of the thermal signal to spread out upstream as well as downstream. The final result is a diluted mass of warm injected water that also sees part of its energy dispersing upstream, thereby leading to less energy within the measurement window downstream and, consequently, producing a lower thermal anomaly (Figure 8).

This study leads to a potentially new approach for field assessment of focused groundwater inflows in small streams with laminar flow and water stages created by obstacles (e.g., weirs, gates, and dams) or by stream 

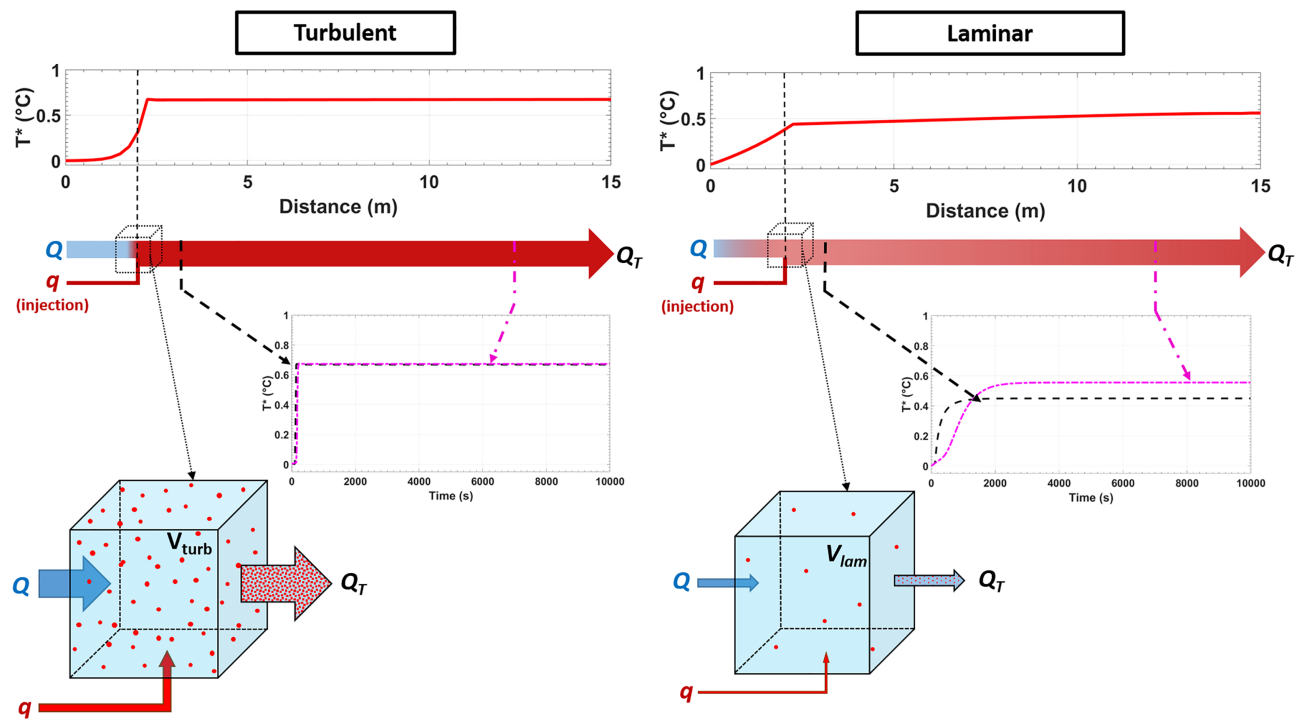

Figure 8. Conceptual diagram of behavior of the injected warm water depending on the flow regime for a given inflow percentage $P$. In a laminar flow regime, a perpendicular injection is diluted in a larger flume volume because of the imposed water stage (weir). The thermal energy is dispersed upstream because of the subcritical flow and the weak advection within the flume. This dilution associated to a heat dispersion leads ultimately to a lower thermal anomaly downstream. Since the strong advective power of a turbulent regime does not allow the injected volume to drift, almost all of the heat is detected downstream. In addition, the injected warm volume is proportionally less diluted for a water stage of $20 \mathrm{~cm}$ or more, increasing the thermal anomaly.

morphology (e.g., ponds). Indeed, it is necessary to determine the flow regime before any temperature survey, since we observed that inflow could be estimated inaccurately if a turbulent flow regime is always assumed. The same is true for atmospheric exchanges and low flow velocities: Large errors are possible when inflow contributes less energy than the atmosphere (i.e., low thermal contrast). Also, the inflow percentage must be large enough to be detectable under laminar flow conditions, unless the thermal contrast between groundwater and stream water is large (equation (7)). For instance, given our FO-DTS configuration, the minimum thermal anomaly detectable would be close to the accuracy of the FO-DTS system (i.e., $0.15{ }^{\circ} \mathrm{C}$ ). For a thermal contrast $\Delta T$ of 1 or $3{ }^{\circ} \mathrm{C}$, the thermal anomaly would yield a detectable inflow percentage of $25 \%$ or $8 \%$, respectively. These examples illustrate that this method for quantifying groundwater-when used under laminar flow-would be relevant only for periods when groundwater supplies most of the water in a stream (e.g., the end of summer). In these examples, measuring thermal anomalies close to the accuracy of the FO-DTS system generally leads to higher uncertainty (Lauer et al., 2013).

Despite its potential—and besides the improvements in the experiments and simulations previously recommended-this approach requires additional developments before using it under field conditions. First, experiments and simulations with cold water inflows are necessary, since such inflows are observed in natural systems in summer. The difficulty in maintaining large volumes of water cold prevented us from using cold water in this study. Since cold injection would involve a density gradient or thermal stratificationespecially at low discharges-3-D or at least 2-D simulations would be necessary. The good mixing between injected water and flume water observed in this study was attributed, for simulations, to the model chosen and, for experiments, to the direct injection method chosen. Thus, for future experiments, injecting water through a medium (e.g., sand bag and artificial bed) is suggested as long as it does not disturb the flow. Finally, determining the volume beyond which the signal is diluted-and whether or not it concerns turbulent flow-might bring great insight into limits of the method under different flow conditions.

\section{Conclusions}

This study combined flume experiments monitored using an FO-DTS system with computer simulations to quantify groundwater inflows into a stream as a function of flow regime. The goal was to determine whether 
this quantification is always compatible with methods that assume perfect mixing with no heat loss (Selker, van de Giesen, et al., 2006) without considering the flow regime. Our results revealed that experiments and simulations under turbulent flow regimes were in accordance with these methods. This study also revealed that such methods would underestimate the inflow percentage under a laminar flow regime. Indeed, laminar flows seem to allow the thermal energy of the inflow to disperse upstream, while the fixed water stage dilutes the inflow in larger volumes than under faster, turbulent flows. The result is a smaller thermal anomaly downstream of the injection point under laminar flow conditions. Atmospheric exchanges were also found to be nonnegligible when the thermal contrast between injected water and flume water was low: for reach lengths as short as $3.5 \mathrm{~m}$, overestimating the inflow percentage by $200 \%$ is possible. A correction using heat-balance equations was necessary to prevent such errors.

These findings can be used to assess small streams during low-flow periods (i.e., end of summer), when groundwater inflows are relatively high and stream morphology or hydrological obstacles (e.g., dams and weirs) create zones with slow velocities and relatively high stages (e.g., ponds). However, further research is required to determine effects of other factors on the detectability or behavior of groundwater inflow into a natural stream. Thus, injections with different imposed water stages or different laminar flow rates should be tested. Finally, injections through sediments of different textures and nonvertical or more diffuse inflows could also be tested. The present results are meant to open the research field to discussion about quantifying groundwater inflows into small streams that have at least periodic laminar flows.

\section{Acknowledgments}

Authors thank the reviewers for their extensive work and constructive remarks that help to significantly improve this manuscript. Data are available at https://www.zenodo.org/ (DOI: 10.5281/zenodo.2632622). This project was funded by the French water agency Agence de l'Eau Loire Bretagne (Contract 150417801)

\section{References}

Anderson, M. P. (2005). Heat as a ground water tracer. Ground Water, 43(6), 951-968. https://doi.org/10.1111/j.1745-6584.2005.00052.x Briggs, M. A., Lautz, L. K., \& McKenzie, J. M. (2012). A comparison of fibre-optic distributed temperature sensing to traditional methods of evaluating groundwater inflow to streams. Hydrological Processes, 26(9), 1277-1290.

Conant, B. (2004). Delineating and quantifying ground water discharge zones using streambed temperatures. Ground Water, 42(2), 243-257. https://doi.org/10.1111/j.1745-6584.2004.tb02671.x

Constantz, J. (1998). Interaction between stream temperature, streamflow, and groundwater exchanges in Alpine streams. Water Resources Research, 34(7), 1609-1615.

Constantz, J. (2008). Heat as a tracer to determine streambed water exchanges. Water Resources Research, 44, W00D10. https://doi.org/ $10.1002 /$ wrcr.20194

Drake, J., Bradford, A., \& Joy, D. (2010). Application of HEC-RAS 4.0 temperature model to estimate groundwater contributions to Swan Creek, Ontario, Canada. Journal of Hydrology, 389(3-4), 390-398.

Dugdale, S. J., Bergeron, N. E., \& St-Hilaire, A. (2013). Temporal variability of thermal refuges and water temperature patterns in an Atlantic salmon river. Remote Sensing of Environment, 136, 358-373.

Dugdale, S. J., Bergeron, N. E., \& St-Hilaire, A. (2015). Spatial distribution of thermal refuges analysed in relation to riverscape hydromorphology using airborne thermal infrared imagery. Remote Sensing of Environment, 160, 43-55.

Ebersole, J. L., Liss, W. J., \& Frissell, C. A. (2003). Thermal heterogeneity, stream channel morphology, and salmonid abundance in northeastern Oregon streams. Canadian Journal of Fisheries and Aquatic Sciences, 60(10), 1266-1280.

Fox, A., Laube, G., Schmidt, C., Fleckenstein, J. H., \& Arnon, S. (2016). The effect of losing and gaining flow conditions on hyporheic exchange in heterogeneous streambeds. Water Resources Research, 52, 7460-7477.

Geist, D. R., Hanrahan, T. P., Arntzen, E. V., McMichael, G. A., Murray, C. J., \& Chien, Y. J. (2002). Physicochemical characteristics of the hyporheic zone affect redd site selection by chum salmon and fall chinook salmon in the Columbia River. North Am. J. Fish Manage., 22(4), 1077-1085.

Genereux, D. P. (1998). Quantifying uncertainty in tracer-based hydrograph separations. Water Resources Research, 34(4), 915-919.

Gonzalez-Pinzon, R., Ward, A. S., Hatch, C. E., Wlostowski, A. N., Singha, K., Gooseff, M. N., et al. (2015). A field comparison of multiple techniques to quantify groundwater-surface-water interactions. Freshwater Science, 34(1), 139-160.

Hare, D. K., Briggs, M. A., Rosenberry, D. O., Boutt, D. F., \& Lane, J. W. (2015). A comparison of thermal infrared to fiber-optic distributed temperature sensing for evaluation of groundwater discharge to surface water. Journal of Hydrology, 530, 153-166.

Henderson, R. D., Day-Lewis, F. D., \& Harvey, C. F. (2009). Investigation of aquifer-estuary interaction using wavelet analysis of fiber-optic temperature data. Geophysical Research Letters, 36, L06403. https://doi.org/10.1029/2008gl036926

Krause, S., Tecklenburg, C., Munz, M., \& Naden, E. (2013). Streambed nitrogen cycling beyond the hyporheic zone: Flow controls on horizontal patterns and depth distribution of nitrate and dissolved oxygen in the upwelling groundwater of a lowland river. Journal of Geophysical Research: Biogeosciences, 118, 54-67.

Lauer, F., Frede, H. G., \& Breuer, L. (2013). Uncertainty assessment of quantifying spatially concentrated groundwater discharge to small streams by distributed temperature sensing. Water Resources Research, 49, 400-407.

Leonard, B. P. (1991). The ultimate conservative difference scheme applied to unsteady one-dimensional advection. Computer Methods in Applied Mechanics and Engineering, 88(1), 17-74.

Lowry, C. S., Walker, J. F., Hunt, R. J., \& Anderson, M. P. (2007). Identifying spatial variability of groundwater discharge in a wetland stream using a distributed temperature sensor. Water Resources Research, 43, W10408. https://doi.org/10.1029/2007wr006145

Mamer, E. A., \& Lowry, C. S. (2013). Locating and quantifying spatially distributed groundwater/surface water interactions using temperature signals with paired fiber-optic cables. Water Resources Research, 49, 7670-7680.

Matheswaran, K., Blemmer, M., Thorn, P., Rosbjerg, D., \& Boegh, E. (2015). Investigation of Stream Temperature Response to NonUniform Groundwater Discharge in a Danish Lowland Stream. River Research and Applications, 31(8), 975-992. 
Mwakanyamale, K., Slater, L., Day-Lewis, F., Elwaseif, M., \& Johnson, C. (2012). Spatially variable stage-driven groundwater-surface wate interaction inferred from time-frequency analysis of distributed temperature sensing data. Geophysical Research Letters, 39 , L06401. https://doi.org/10.1029/2011gl050824

Neilson, B. T., Hatch, C. E., Ban, H., \& Tyler, S. W. (2010). Solar radiative heating of fiber-optic cables used to monitor temperatures in water. Water Resources Research, 46, W08540. https://doi.org/10.1029/2009wr008354

Selker, F., \& Selker, J. S. (2014). Flume testing of underwater seep detection using temperature sensing on or just below the surface of sand or gravel sediments. Water Resources Research, 50, 4530-4534. https://doi.org/10.1002/2014wr015257

Selker, J., van de Giesen, N., Westhoff, M., Luxemburg, W., \& Parlange, M. B. (2006). Fiber optics opens window on stream dynamics. Geophysical Research Letters, 33, L24401. https://doi.org/10.1029/2006gl027979

Selker, J. S., Thevenaz, L., Huwald, H., Mallet, A., Luxemburg, W., de Giesen, N. V., et al. (2006). Distributed fiber-optic temperature sensing for hydrologic systems. Water Resources Research, 42, W12202. https://doi.org/10.1029/2006wr005326

Selker, J. S., Tyler, S., \& van de Giesen, N. (2014). Comment on "Capabilities and limitations of tracing spatial temperature patterns by fiber-optic distributed temperature sensing” by Liliana Rose et al. Water Resources Research, 50, 5372-5374.

Smith, J. W. N., Bonell, M., Gibert, J., McDowell, W. H., Sudicky, E. A., Turner, J. V., \& Harris, R. C. (2008). Groundwater-surface water interactions, nutrient fluxes and ecological response in river corridors: Translating science into effective environmental management. Hydrological Processes, 22(1), 151-157.

Tyler, S. W., Selker, J. S., Hausner, M. B., Hatch, C. E., Torgersen, T., Thodal, C. E., \& Schladow, S. G. (2009). Environmental temperature sensing using Raman spectra DTS fiber-optic methods. Water Resources Research, 45, W00D23. https://doi.org/10.1029/2008wr007052

van de Giesen, N., Steele-Dunne, S. C., Jansen, J., Hoes, O., Hausner, M. B., Tyler, S., \& Selker, J. (2012). Double-ended calibration of fiberoptic raman spectra distributed temperature sensing data. Sensors, 12(5), 5471-5485. https://doi.org/10.3390/s120505471

Vidon, P., Allan, C., Burns, D., Duval, T. P., Gurwick, N., Inamdar, S., et al. (2010). Hot spots and hot moments in riparian zones: Potential for improved water quality management. JAWRA Journal of the American Water Resources Association, 46(2), $278-298$.

Westhoff, M. C. (2011). High resolution temperature observations to identify different runoff processes (138 pp.). Faculty of Civil Engineering and Geosciences.

Westhoff, M. C., Bogaard, T. A., \& Savenije, H. H. G. (2011). Quantifying spatial and temporal discharge dynamics of an event in a first order stream, using distributed temperature sensing. Hydrology and Earth System Sciences, 15(6), 1945-1957.

Westhoff, M. C., Savenije, H. H. G., Luxemburg, W. M. J., Stelling, G. S., van de Giesen, N. C., Selker, J. S., et al. (2007). A distributed stream temperature model using high resolution temperature observations. Hydrology and Earth System Sciences, 11(4), 1469-1480.

Zarnetske, J. P., Haggerty, R., Wondzell, S. M., \& Baker, M. A. (2011). Dynamics of nitrate production and removal as a function of residence time in the hyporheic zone. Journal of Geophysical Research, 116, G01025. 